\title{
From the Sun's atmosphere to the Earth's atmosphere: an overview of scientific models available for space weather developments
}

\author{
C. Lathuillère ${ }^{1}$, M. Menvielle ${ }^{2,}$, J. Lilensten ${ }^{1}$, T. Amari ${ }^{3}$, and S. M. Radicella ${ }^{4}$ \\ ${ }^{1}$ Laboratoire de Planétologie de Grenoble, CNRS/UJF/OSUG, Batiment D de Physique, BP 53, 38041 Grenoble Cedex 9 , \\ France \\ ${ }^{2}$ Centre d'études des Environnements Terrestre et Planétaires, CNRS/UVSQ, 4 avenue de Neptune, 94100 St Maur, France \\ ${ }^{3}$ Centre de Physique Théorique, Ecole Polytechnique, 91128 Palaiseau Cedex, France \\ ${ }^{4}$ Aeronomy and Radiopropagation Laboratory Abdus Salam International Centre for Theoretical Physics, Strada Costiera 11, \\ 34014 Trieste, Italy \\ *and at: Université Paris-Sud, Orsay, France
}

Received: 21 August 2001 - Revised: 27 March 2002 - Accepted: 3 April 2002

\begin{abstract}
Space weather aims at setting operational numerical tools in order to nowcast, forecast and quantify the solar activity events, the magnetosphere, ionosphere and thermosphere responses and the consequences on our technological societies. These tools can be divided in two parts. The first has a geophysical base (Sun, interplanetary medium, magnetosphere, atmosphere). The second concerns technological applications (telecommunications, spacecraft orbits, power plants ...). In this paper, we aim at giving an overview of the models that belong to the first class (geophysics) that might serve in the future as a basis for building global operational codes. For each model, we consider the physics underneath, the input and output parameters, and whether it is already operational, whether it may become operational in the near future, or if it is an academic research tool. Relevant references are given in order to serve as a starting point for further readings.
\end{abstract}

Key words. Interplanetary physics (general or miscellaneous), Ionosphere (modelling and forecasting), Magnetospheric physics (general or miscellaneous)

\section{Introduction}

Reviewing the current state of scientific models available for space weather developments is actually an extremely ambitious task. It covers a broad range of topics - from the Sun to the Earth - and of techniques and methods - from the ideal Magnetohydrodynamics (MHD) to particle behaviour modelling. To do a thorough job would have required a book. However, the range of topics involved in space weather makes it necessary to have introductory documents that pro-

Correspondence to: C. Lathuillère

(Chantal.Lathuillere@obs.ujf-grenoble.fr) vide the non-specialist with basic features and relevant references on the various issues.

The present work aims at providing an overview of the models which might serve as a basis to build global operational codes for practical space weather prediction. Our objective is to provide the reader with basic features on the various issues, and not to deal with each of them in any sufficient or satisfying detail for a specialist. It is also to give relevant references that can serve as a starting point for those who are interested in specific topics.

This paper has been written from the work package entitled "Space Weather Parameters", prepared as part of a study conducted by the consortium lead by ALCATEL Space \& LPCE (France) in the frame of an ESA contract aiming at the definition of an European Space Weather Programme. All work packages have received the contribution from the different consortium members (see Annex 1 for a presentation of the consortium). A parallel study has been undertaken by another consortium led by the Rutherford Appleton Laboratories (UK). Among the tasks of the consortium was to define the parameters and the associated measurements, which are necessary to describe and monitor the Sun-Earth system in the space weather context.

Space weather can be considered from two different standpoints, the numerical modelling of the whole system on the one hand, and the needs of the users, i.e. monitoring and forecasting the values of some specific quantities, on the other hand. Our approach has been to start with a review of the modelling effort, which is presented in this paper.

The driving source of the Solar Terrestrial phenomena is the Sun's magnetic field. The related magnetic energy is converted into thermal and kinetic energy, and gives rise to electromagnetic and particle solar radiations. The plasma that is ejected from the upper solar atmosphere is accelerated to supersonic speeds, and the Sun's magnetic field lines are frozen 
in the plasma. The Earth's magnetic field behaves as a solid obstacle for the plasma. It gives rise to the magnetospheric cavity around which the solar wind flows, with energy and material exchange through the magnetosphere boundary. Finally, both magnetospheric plasma and solar electromagnetic radiations interact with the Earth's atmosphere, giving rise to the ionosphere and thermosphere. This very short summary shows that the entire Solar-Terrestrial system can be described and understood in terms of a succession of subsystems that exchange material and energy: the Sun's atmosphere, the interplanetary medium, the magnetosphere, and finally, the ionosphere-thermosphere system. Figure 1 shows a schematic description of the solar-terrestrial phenomena in terms of the interaction between these sub-systems.

The elucidation of the physical processes involved in each sub-system, and in the interaction between any two of them, is an important key in any space weather program. Our understanding of the whole Sun-Earth system is, however, still incomplete, although research and operational models are available. There exist research models for each sub-system, but their maturity is very different, depending on the complexity of physical phenomena and on the available observations. Operational models have already been developed only for some sub-systems. Our aim is not to present an exhaustive list of models but rather to give a comprehensive picture of the modelling effort of the different scientific communities concerned by space weather.

We have chosen to organise our presentation by classifying for each sub-system the models in two main classes:

- the empirical models that characterise the relations between relevant parameters from available observations;

- the physical models that describe a given sub-system on the basis of quantitative laws between relevant parameters. Contrary to the empirical models, the relations between parameters are expressed in terms of a priori known physical laws, with relevant simplifications, if any. They are expressed as a set of partial derivative equations, with coefficients to be estimated.

Recently developed space weather models based upon artificial techniques, such as neural networks genetic algorithms and expert systems, are not presented here, nor are the technological models which estimate the specified effects of our environment on a given "system", for example, those dealing with radiation doses, spacecraft charging, proton fluences or atmospheric drag.

In this paper, we consider successively the different subsystems that are involved in solar-terrestrial relations: the Sun, the interplanetary medium, the magnetosphere, and the ionosphere-thermosphere system. The last section of the paper presents a model synthesis, by means of tables that outline their main characteristics, including their input and output parameters.

\section{The Sun}

Most of the structures and phenomena present in the solar atmosphere - in particular eruptive phenomena, such as flares and coronal mass ejections (CMEs) - result from the presence of a dominant magnetic field. Eruptive events correspond to a liberation of magnetic energy stored in the solar corona. This energy is then converted into:

- heating of the environment associated with UV/EUV and $\mathrm{X}$ beams;

- particle accelerations (electrons and ions) associated with an $\mathrm{X}$ emission when those particles interact with the environment;

- movement of matter.

Solar flares correspond to localised phenomena covering at most a few percent of the surface of the Sun, while CMEs are larger scale phenomena that can involve a non-negligible part of the Sun's global configuration. Those may have different origins and associated events, such as global magnetic nonequilibrium or prominence disruption.

The global solar atmospheric models are developed mainly in the framework of Magnetohydrodynamics (MHD). The relevant set of equations describes the interaction of ionised coronal plasma with the coronal magnetic field in the presence of the plasma pressure and gravity forces. These models may be presented in the context of space weather, although they are still essentially used for theoretical purposes. The associated numerical codes are mostly research tools due to the actual state of the art in solar MHD modelling. We present thereafter two main classes of complementary models used for different purposes: the static models for equilibrium reconstruction of the solar coronal magnetic field and the dynamic models to describe its evolution:

- the first class of models arises from the impossibility of measuring the coronal magnetic field. The structure of the active regions should be estimated before an eruptive event, in order to determine the intrinsic properties of the magnetic configuration. Thus, one has to reconstruct the coronal magnetic field and, therefore, to solve the equations of the solar atmospheric physics when the boundary conditions are the values of the magnetic field measured in the colder photosphere by vector magnetographs;

- the second class of models aims at studying the dynamical evolution of the active regions. The energy storage and energy release in these regions, as well as their stability, are described from the evolution of the magnetic configurations which are constrained by a driver whose origin may be sub-photospheric (emerging flux), photospheric (boundary motions) or coronal (interaction with other active regions). These models solve - to a certain extent - the full MHD equations. 


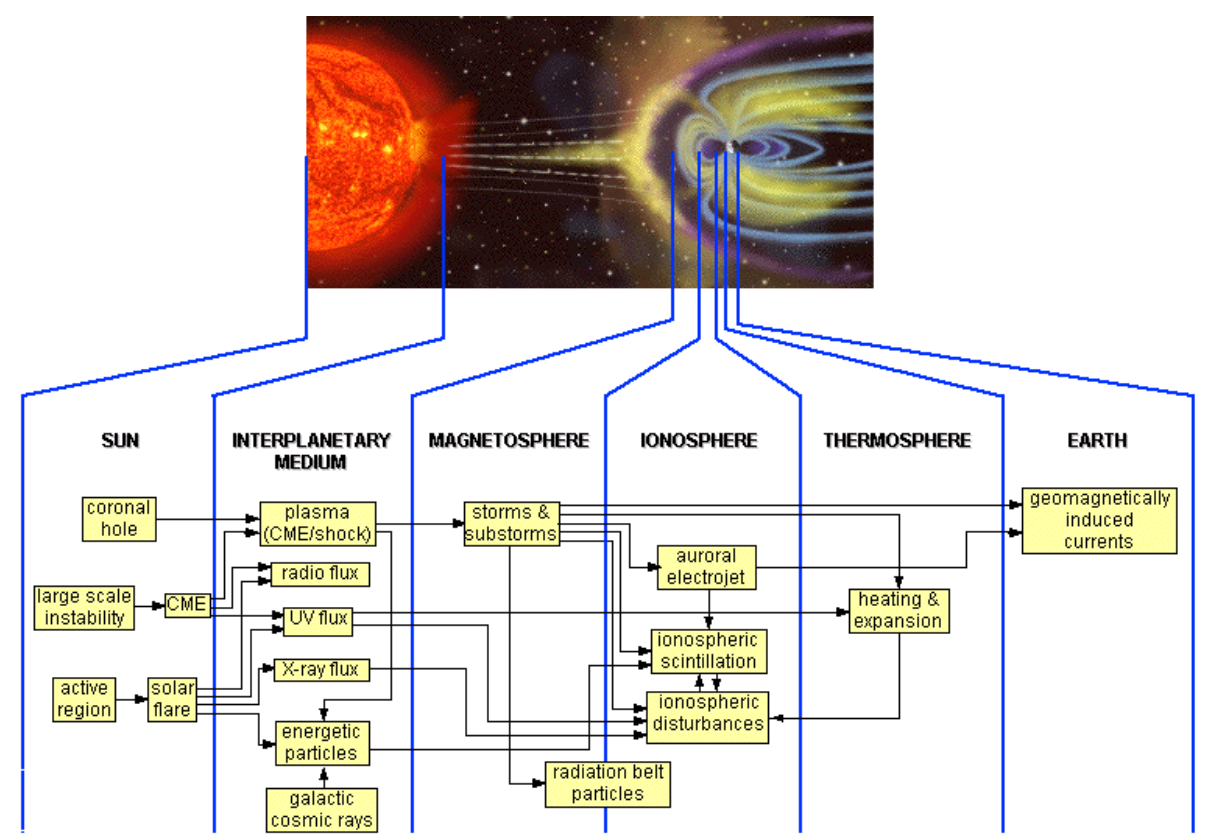

Fig. 1. Main physical processes that act on space weather (Dudok de Wit, personal communication, 2001).

Both classes of models are complemented by a whole set of boundary conditions which then define a set of boundary value problems.

\subsection{Reconstruction and study of the active region static} structures

Equilibrium reconstruction of the coronal magnetic field above active regions using photospheric magnetic data has been the subject of numerous studies since the first attempts (Schmidt, 1964). They may range from observational problems, such as those related to the $180^{\circ}$ ambiguity resolution, which remains on the transverse component of the photospheric magnetic field, to crucial theoretical problems related to the nature and the determination of the correct type of boundary conditions that have to be used in order to avoid an ill-posed problem, as was the case for a long time. Details and numerous relevant aspects of these studies are discussed in Amari and Démoulin (1992) and Amari et al. (1997).

In an active region, prior to any eruptive event, typical time variations are so small that one can then solve the MHD equations under static hypothesis. The coronal magnetic pressure is much larger than the gas one, and gravity can be neglected outside prominences. This is the so-called forcefree approximation. This is equivalent assuming that at any point the current density and the magnetic field are parallel. The proportionality factor $\alpha(\boldsymbol{r})$ and the magnetic field are determined by the boundary conditions defining the boundary value problem.

In the regions of higher density, the plasma pressure gradients and the gravity have been included. This can be done self-consistently in full MHD methods or more qualitatively by seeking magnetohydrostatic solutions of the MHD equations.

\subsubsection{Current free (potential) model}

The simplest physical approximation is the so-called "current free" approximation $(\alpha=0)$, which only requires the longitudinal photospheric component of the magnetic field as a boundary condition. It was first considered by Schmidt (1964) and is currently routinely used in most of the terrestrial solar physics centres, on the basis of observations (Sakurai, 1989). It is also used as the initial conditions for fundamental MHD studies dealing with synthetic problems. This kind of reconstruction is performed following a Green function approach or using a Laplace solver to compute a potential scalar function and the associated magnetic field (Priest, 1982).

\subsubsection{Linear force-free model}

The zero-current approximation does not apply to many active regions that have a magnetic energy above the minimum energy, which corresponds to the current free field for the same distribution of the vertical distribution of the photospheric normal magnetic field. The first step towards a more realistic modelling consists of considering a nonzero, but constant $\alpha$ that allows one to introduce coronal electric currents. Different methods exist that use the longitudinal component of the magnetic field. They are based on Green functions (Chiu and Hilton, 1977) or Fourier transform (Alissandrakis, 1981), with the latter currently used (Demoulin et al., 1997). Following the general approach of Low (1992), this linear constant- $\alpha$ Fourier method has been extended to take into account gravity and pressure forces by means of a linear computational program (Demoulin et al., 1997; Aulanier et al., 1998). 
Although they suffer from several limitations (see below), linear models can be used for some classes of problems (topology, prominence) in moderately sheared structures. Their main advantage remains the weak computational resources they need and their computational speed for the current free approximation, which explains why they could be used routinely in a space-weather program.

\subsubsection{Nonlinear force-free model}

As for the reconstruction without current, several limitations exist regarding the use of the linear reconstruction model:

- the solutions correspond to a minimisation problem for the energy, constrained by the normal component of the magnetic field and by the total magnetic helicity, inducing a limited amount of available magnetic free energy;

- the electric currents cannot be locally intense, while the observations show very clearly important localised shear concentrated along the inversion line of the normal component of the photospheric magnetic field.

The only hope of incorporating large localised electric currents is to assume that the configuration is in a nonlinear force-free state, that is to say that $\alpha$ (which now depends on the position $\boldsymbol{r}$ ) is also an unknown of the problem. Different types of boundary conditions define different boundary value problems and codes:

- a first relatively natural method consists of imposing the three components of the magnetic field $\boldsymbol{B}$ measured at the photospheric level. The problem amounts to progressively extrapolating the data step by step toward the corona. This is the vertical integration method introduced by $\mathrm{Wu}$ et al. (1990). However, this method is based on a mathematical formulation associated with an ill-posed boundary value problem. This lead to an exponential divergence, which limits the reconstruction at low altitudes. Some methods have been proposed in order to avoid this divergence (Cuperman et al., 1990; Demoulin et al., 1992). Other attempts have been made to regularise the linear version of this method (Amari et al., 1998);

- a second class of reconstruction methods is based on a well-posed formulation, which corresponds to observed boundary conditions that imply:

- the normal component of the photospheric magnetic field (in the local system of reference associated with the Sun);

- $\alpha$ at the photospheric level, when the sign of the normal component $B_{z}$ of the measured magnetic field has a given a priori value: as an example, $\alpha$ is set in the areas where $B_{z}$ is positive and then computed through transport along the magnetic field lines to the photospheric zones where $B_{z}$ is negative.
This kind of mathematical formulation was introduced by Grad and Rubin (1958) and consists of a decomposition of the nonlinear problem in two sets of elliptical (for the magnetic field) and hyperbolic (for $\alpha$ ) problems. It gives rise to two types of numerical codes, which correspond to the Lagrangian and Eulerian approaches:

- Sakurai (1981) uses a Lagrangian approach for each field line. He injects progressively the photospheric electric current on each field line;

- Amari et al. (1997) use a global approach in order to solve the elliptical and hyperbolic problems. The corresponding codes with their different versions constitute the EXTRAPOL code.

These two codes, localised in Japan and in France, are used to reconstruct the configurations of the active regions coming from MITAKA data for the Japanese version and from Hawaii (HSP, IVM) and Boulder (ASP) for the French one. The local Lagrangian approach (Japan) seems to imply a more important limit for the reproducible maximum shearing than the Eulerian approach (France);

- a third class of methods is based on solving the MHD equations, injecting the vertical component of the electric current and imposing the normal component of the magnetic fields as photospheric boundary conditions. The system relaxes toward a state which corresponds to the observed values. This method is called the "resistive-relaxation" method. It was introduced by Mikic and Linker (1994) and was also implemented in the French METEOSOL MHD-research code. Although the mathematical justification for this method is not yet clear, the corresponding codes have been used on real cases with relatively good success;

- another method is still at a very experimental state of development. It is the "weighted residue method" (Pridmore-Brown, 1981). This method minimises two residuals: one is associated with the magnetic force, and the second one is associated with the difference between the directions of the photospheric transverse components of the computed and observed magnetic fields. This method has been used only in theoretical situations corresponding to fictive periodic data;

- finally, a method called "constraint and relaxation method" (Roumeliotis, 1996) consists of two repeated steps:

- impose on the vector potential the minimisation of the difference between the computed and observed transverse components;

- relax toward an equilibrium state, using a relaxation code which incompletely solves the MHD equations,

- then, back to the first step. 
Table 1. A synthesis of MHD codes for the evolution of the solar magnetic configurations

\begin{tabular}{|c|c|c|}
\hline Laboratories & Characteristics & Aims \\
\hline $\begin{array}{l}\text { San Diego (USA) } \\
\text { (Mikic and Linker, 1994) }\end{array}$ & $\begin{array}{l}2.5 \mathrm{D}, 3 \mathrm{D} \\
\text { Finite differences } \\
\text { Semi-implicit }\end{array}$ & coronal MHD \\
\hline $\begin{array}{l}\text { NRL et NASA (Wash. DC) } \\
\text { (De Vore et al., 2000) }\end{array}$ & $\begin{array}{l}2.5 \mathrm{D}, 3 \mathrm{D} \\
\text { Spectral + finite volumes } \\
\text { Explicit } \\
\text { Boundary conditions }(\ldots)\end{array}$ & Coronal and internal MHD \\
\hline $\begin{array}{l}\text { Japan NAO/Mikata } \\
\text { (Matsumoto et al., 1993) }\end{array}$ & $\begin{array}{l}2.5 \mathrm{D}, 3 \mathrm{D} \\
\text { Explicit } \\
\text { artificial viscosity } \\
\text { anomalous }\end{array}$ & $\begin{array}{l}\text { Chromospheric and internal } \\
\text { MHD }\end{array}$ \\
\hline $\begin{array}{l}\text { Observatoire de Meudon } \\
\text { Ecole Polytechnique (France) } \\
\text { (Amari et al., 2000) }\end{array}$ & $\begin{array}{l}\text { 2.5D, 3D } \\
\text { differences and finite volumes } \\
\text { (semi) and implicit }\end{array}$ & coronal MHD \\
\hline $\begin{array}{l}\text { Strasbourg (France) } \\
\text { (Baty and Heyvaerts, 1996) }\end{array}$ & $\begin{array}{l}\text { cylindrical } \\
\text { Boundary conditions }\end{array}$ & $\begin{array}{l}\text { coronal MHD } \\
\text { stability }\end{array}$ \\
\hline $\begin{array}{l}\text { Pisa / Firenze (Italy) } \\
\text { (Lionello et al., 1998) }\end{array}$ & $\begin{array}{l}\text { cylindrical (3D) San Diego } \\
2 \mathrm{D} \text { reduced MHD }\end{array}$ & $\begin{array}{l}\text { coronal MHD } \\
\text { turbulence }\end{array}$ \\
\hline $\begin{array}{l}\text { Nice (France) } \\
\text { (Galtier et al., 1997) }\end{array}$ & $\begin{array}{l}\text { 1D, 2D } \\
\text { Finite differences, Spectral }\end{array}$ & $\begin{array}{l}\text { Turbulence } \\
\text { Intermittence }\end{array}$ \\
\hline $\begin{array}{l}\text { Argentina } \\
\text { (Dmitruk et al., 1998) }\end{array}$ & $\begin{array}{l}\text { Reduced MHD (2D+) } \\
\text { Cartesian } \\
\text { Spectral (Fourrier) }\end{array}$ & $\begin{array}{l}\text { Turbulence } \\
\text { Flare-heating }\end{array}$ \\
\hline $\begin{array}{l}\text { University of Michigan (USA) } \\
\text { (Israelevich et al., 2001) }\end{array}$ & $\begin{array}{l}\text { 2D, } 2.5 \mathrm{D}, 3 \mathrm{D}(?) \\
\text { Roe scheme } \\
\text { Finite volumes }\end{array}$ & $\begin{array}{l}\text { Comets - wind } \\
\text { astrophysics }\end{array}$ \\
\hline $\begin{array}{l}\text { NCSA (Illinois) } \\
\text { (Stone and Norman, 1992) }\end{array}$ & $\begin{array}{l}\text { 2.5D, (3D ?) } \\
\text { Finite volumes } \\
\text { Van Leer, PPM }\end{array}$ & $\begin{array}{l}\text { Astrophysics } \\
\text { laboratories }\end{array}$ \\
\hline $\begin{array}{l}\text { DAEC + DESPA (France) } \\
\text { (Grappin et al., 2000) }\end{array}$ & $\begin{array}{l}\text { cylindrical /(Spherical 2.5D) } \\
\text { Z-periodic } \\
\text { Spectral - Finite differences }\end{array}$ & $\begin{array}{l}\text { Dynamo + wind } \\
\text { laboratories }\end{array}$ \\
\hline $\begin{array}{l}\text { Chicago (USA) } \\
\text { (Fryxell et al., 2000) }\end{array}$ & cartesian & $\begin{array}{l}\text { Astrophysics } \\
\text { laboratories }\end{array}$ \\
\hline
\end{tabular}

This method has been tested with encouraging results on a theoretical case, as well as on an observed active region.

\subsection{Evolution of the magnetic configurations}

As far as the evolution of the magnetic configurations is concerned, the MHD codes belong to the domain of research even more than the reconstruction codes. It concerns the fundamental numerical research for the codes themselves: boundary conditions, geometry, temporal scheme, mesh definition, etc., but also the fundamental solar physics. The objective is to elucidate the fundamental mechanisms that govern the eruptive phenomena: flux emergence, energy storage, influence of the photospheric movements such as differential rotations or magnetic reconnection, etc.

The existing codes depend on the different classes of problems they address: there is no universal MHD code, in the same way as there is no universal telescope. However, it will still be a long time before the MHD codes can be used for space weather purposes, in order to test the stability of the magnetic configurations in active regions. These regions may be first reconstructed by using an equilibrium reconstruction code. This is the approach followed by some groups.

The existing world wide codes can be distinguished by the following characteristics: 
- dimension: 2D, 2.5D, where the vectors have 3 components but only depend on 2 space variables, 3D;

- geometry: spherical for the global models, Cartesian for the description of the active regions at local scales, cylindrical for more specific problems, such as the stability of the coronal loops or of the coronal heating;

- numerical scheme and space digitisation: finite elements, finite volumes, spectral methods, collocation, etc.

- physical approach: heating, resistivity, solar wind inclusion facing the particularly important and difficult problem of breakdown of the MHD approximation.

Table 1 only attempts to synthesize these different approaches worldwide. We are aware that on-going work may give rise to new codes in the near future. We only show here the codes and the associated developing groups and give only one reference per group, as a starting point. The more numerous groups that only use the codes are excluded from the table.

\section{The interplanetary medium}

The solar wind is a prominent part of the Sun-Earth system that is difficult to model because observations are difficult and often indirect. The solar wind corresponds to the outflow from the upward solar atmosphere of the coronal plasma, heated up to several million K. Its speed ranges between 250 and $950 \mathrm{~km} \cdot \mathrm{s}^{-1}$ at the Earth's orbit (1 AU). It is structured by the Sun's magnetic field lines frozen in the flow. The solar wind interacts in the interplanetary medium with galactic cosmic rays. Since the solar wind expansion does not occur in a vacuum but in an interstellar space filled with neutral and ionised gases, galactic cosmic rays and galactic magnetic fields, the region where the solar wind dominates is limited by the heliospheric boundary - a region where the energy densities of the solar wind and the interstellar space are equal. This boundary is located between about 50 and $100 \mathrm{AU}$.

\subsection{Solar wind modelling}

The main structures or regions present in the solar wind are:

- the high velocity solar wind, associated with the coronal holes;

- the low velocity solar wind;

- the regions of interactions between high and low velocity solar winds;

- the heliospheric current sheet;

- the signatures in the interplanetary medium of the CMEs, associated or not associated with shocks. In practice, these signatures are observed at large distances from the Sun near the Earth or the Lagrange point L1.
The influence of the solar wind results from both its very structure and its interaction with the propagation of solar perturbations, such as energetic particles resulting from solar eruptions or interplanetary shocks or CMEs. The structure of the interplanetary magnetic field lines, which drives the particle propagation, may, in given situations, dramatically affects this propagation and, therefore, the resulting effects at Earth. This ambivalent action can be illustrated by examples of major events at the Sun with minor effect's at the Earth, or on the contrary, minor events at the Sun resulting in a major perturbation at the Earth.

Solar wind models have been developed to address many aspects of its structure. Fairly simple models can be developed by treating the solar wind from a hydrodynamic point of view, and thus solving the one-dimensional equations of motion along a single field line (e.g. Parker, 1963). The main aim of such models is to obtain accurate expressions for the plasma density, velocity, and especially temperature at $1 \mathrm{AU}$. They are also amenable to adding multiple ion species and to including quite detailed calculations of different ionisation states and even the effect of plasma instabilities on the temperatures.

However, from the point of view of space weather, it is the large-scale multi-dimensional MHD models that are the most relevant. One class of these models examines the global structure of the solar wind plasma and magnetic field in the heliosphere. These models are quasi-steady state, but incorporate solar rotation, and a three-dimensional magnetic field. For solar minimum conditions - for which they are best suited - they clearly demonstrate the formation of the familiar co-rotating interaction regions at distances of $1 \mathrm{AU}$ and beyond (Pizzo, 1982, 1991). The Ulysses mission has permitted a comparison of these results with the threedimensional solar wind structure. The agreement is good, especially in terms of plasma flows upward and downward from the ecliptic plane (Riley et al., 1996).

A second family of models deals with the motion of coronal mass ejections in the solar wind. The goal is, for given plasma and magnetic field conditions at the Sun, to calculate the properties of the CME at $1 \mathrm{AU}$ and beyond. Early models treated the CME as a pressure pulse, but these are now viewed as irrelevant. Other purely hydrodynamic models have been developed by Riley and collaborators during an investigation of so-called over-expanding CMEs. They showed that with a large plasma over-pressure at the Sun, the conditions observed by the Ulysses spacecraft at large distances could be roughly reproduced (Riley et al., 1997).

The most geo-effective type of CMEs are magnetic clouds. Models for these have been developed by a number of groups who have - in general terms - established that magnetic clouds can propagate from the Sun to the Earth while retaining their organised magnetic structure (e.g. Cargill et al., 2000; Odstrcil and Pizzo, 1999; Vandas et al., 1996). The clouds interact with the solar wind by two processes. First, the cloud magnetic field can undergo magnetic reconnection with the solar wind field, leading to its ultimate destruction at large distances. Second, the interaction of the cloud with the 
solar wind plasma leads to considerable changes in its shape, as well as leading shock waves. This modelling is plagued by difficulties in initialising the solar wind magnetic field in a way that minimises errors in the $\operatorname{div} \boldsymbol{B}=0$ condition. Proper 3-D modelling actually requires that this problem be resolved. Further discussion of such CME models can be found in Cargill and Schmidt (this issue).

Among the empirical models, one can quote WangSheeley, based upon the discovery of an anti-correlation between the solar wind velocity and the rate of expansion of the magnetic flux tubes (Wang and Sheeley, 1992). The model is based on observations of magnetographs at the Sun's surface and on deduced maps of coronal holes, surface magnetic field sources and solar wind velocity. It forecasts the IMF polarity and the solar wind velocity at the Earth, two parameters that are mandatory for geomagnetic activity forecasting ${ }^{1}$.

\subsection{Solar wind - cosmic ray interaction}

Cosmic rays at the Earth are high energy particles - from $500 \mathrm{MeV}$ to about $10^{12} \mathrm{GeV}$ - insensitive to the magnetosphere state. The main components are protons, electrons and light nuclei. Below about $1 \mathrm{Ge} \mathrm{V} /$ nucleon, the cosmic ray flux is strongly decreased due to adiabatic deceleration with the solar wind, which results a decreasing flux below this energy at the Earth's orbit. The intensity of the cosmic rays on the Earth maximises when solar activity is minimal (quiet Sun) and minimises vice versa (active Sun), with an average variation in intensity of about $20 \%$.

Models describing the propagation of the cosmic rays through the solar wind are based on a second order equation whose main input parameters are the solar wind characteristics and the interplanetary magnetic field. Fisk et al. (1998) show that most of the observed phenomena can be accounted for within acceptable ranges of these parameters. However, no single model, with a single choice for the input parameters, has been able to account for all the observed features of galactic and anomalous cosmic ray behaviour. The most highly developed models concern the interpretation of longterm variations of the flux of cosmic rays at the Earth.

\section{The magnetosphere}

The magnetosphere is the region of the ionised environment of the Earth where the Earth's magnetic field has a dominant control over the motion of charged particles. The boundary layer between the magnetosphere and the solar wind is the magnetopause, at which the dynamic pressure of the solar wind is balanced by the magnetic pressure of the Earth's magnetic field ${ }^{2}$. The location of the magnetopause obviously

\footnotetext{
${ }^{1}$ http://solar.sec.noaa.gov/ narge/

${ }^{2}$ The dynamic pressure of the solar wind is $2 \rho V^{2} \cos ^{2} \chi$, where $\rho$ and $V$ are the solar wind density and velocity, and $\chi$ is the angle between the direction of the solar wind velocity and that of the normal to the magnetopause; the magnetic pressure of the Earth's magnetic field is $B^{2} / 2 \mu$, where $B$ is the tangential component of
}

depends on the status of the solar wind. Under typical solar wind conditions, the terrestrial magnetosphere extends up to $\sim 10$ Earth radii $\left(R_{E}\right)$ in the sunward direction and to several hundreds $R_{E}$ in the antisunward direction. The solar wind velocity is supersonic at $1 \mathrm{AU}$, and the magnetosphere behaves as a solid obstacle. Therefore, there is a bow shock upstream from the magnetopause. In the solar direction, the bow shock is located at a distance in the range of 2-4 $R_{E}$ from the magnetopause. The region between the bow shock and the magnetopause is the magnetosheath, in which the shocked solar wind plasma has a lower velocity and a temperature 5 to 10 times higher than in the solar wind.

The inner magnetosphere is the region of major concern for space weather issues. Three regions have been identified there following different criteria: the plasmasphere, the radiation belts, and the ring current:

1. the plasmasphere corresponds to a cold $\left(T_{e} \approx 1 \mathrm{eV}\right)$ but dense $\left(n_{e} \approx 5 \times 10^{2} \mathrm{~cm}^{-3}\right)$ plasma which co-rotates with the Earth. It is a torus-shaped volume in the innermost magnetosphere. The outer boundary of the plasmasphere is the plasmapause, where the density sharply drops down to about $1 \mathrm{~cm}^{-3}$. On average, the plasmapause is located about $4 R_{E}$ in the equatorial plane, i.e. a McIlwain parameter ${ }^{3} L=4$. It may reach out to $L=5-6$ during periods of magnetospheric quietness and be compressed down to $L=3$ during periods of intense magnetospheric activity;

2. the ring current refers to "those parts of the particles in the inner magnetosphere which contribute substantially to the total current density" (Hultqvist et al., 1999). It is then defined with regard to its magnetic signature, and corresponds to a toroidal-shaped electric current that flows westwards around the Earth, with variable density at geocentric distances between $\sim 2 R_{E}$ and $\sim 9 R_{E}$. During magnetospheric storms, the particles that contribute substantially to the total current density are mainly trapped ions in the medium energy range (few tens of $\mathrm{keV}$ to few hundreds of $\mathrm{keV}$ ) that originate in the solar wind $\left(\mathrm{He}^{++}\right)$, the plasmasphere and the ionosphere $\left(\mathrm{O}^{+}\right)$. During low activity periods, the particles responsible for the ring current are mostly protons. This change in composition impacts the evolution with time of the ring current, because loss mechanisms (wave-particle interactions, charge exchange, Coulomb collisions, etc.) depend on the mass and energy of the particles;

3. the radiation belts generally refer by now to the "high energy ions and electrons that can penetrate into spacecraft shielding materials and eventually cause radiation damage to spacecraft instrumentation and to humans"

the Earth's magnetic field at the magnetopause. $\mu$ is the magnetic permeability of the medium.

${ }^{3}$ For a given geomagnetic field line, the Mac Ilwain parameter $L$ is the geocentric distance of the point where it crosses the magnetospheric equator. It is expressed in Earth radii $\left(R_{E}\right)$. 
(Hultqvist et al., 1999). The radiation belts are defined with regard to the energy of particles trapped in the geomagnetic field lines, above $\sim 100 \mathrm{keV}$ and reaching values of hundreds of $\mathrm{MeV}$. Most of the trapped particles are protons and electrons, giving rise to the proton and electron radiation belts:

- the proton belt has generally one maximum, which corresponds to a McIlwain parameter $L$ that decreases with increasing proton energy. For $1 \mathrm{MeV}$, the maximum corresponds to $L \sim 2.5$ (i.e. field lines crossing the equatorial plane at an altitude $h_{e q}$ of $\sim 10000 \mathrm{~km}$ ), while it corresponds to $L \sim 1.4$ (i.e. $h_{e q} \sim 2500 \mathrm{~km}$ ) for $50 \mathrm{MeV}$. The proton belt is fairly stable. At low altitude, it is modulated by the solar cycle, in particular in the region of the South Atlantic magnetic anomaly: its intensity is maximum during solar minimum, and minimum during solar maximum. Major magnetic storms (e.g. March 1991) may significantly impact the proton belts, in particular for high McIlwain parameters values;

- the electron belt has generally two maxima, giving rise to the internal and external electron belts. The internal belt, with a maximum corresponding to $500 \mathrm{keV}$ around $L \sim 1.4$ (i.e. $h_{e q} \sim 6400 \mathrm{~km}$ ), does not significantly vary with time. On the contrary, the external belt, the maximum of which is around $L \sim 4$ (i.e. $h_{e q} \sim 19000 \mathrm{~km}$ ) fluctuates dramatically under the control of strong magnetic storms: short-term variations of the flux, up to 4 orders of magnitude in a few hours, can be observed during periods of intense magnetic activity. The long-term variation of the external belt fluxes is driven by the solar cycle: the annual mean values of the flux are maximum during the descending phase (about 3 years after the maximum), when coronal holes are in good conjunction with the Earth.

It is worth noting that ring current, radiation belts and the plasmasphere partially overlap. For instance, at $L=3$, the density of the cold plasma is about 1000 times higher than the density of energetic protons $(>100 \mathrm{keV})$, whereas the energy density of energetic protons dominates by a factor of about 1000 . It is also worth noting that trapped radiation belts and the ring current are actually closely related, since the major part of the ring current is carried by trapped particles and all the trapped particles contribute to the ring current (Hulqvist et al., 1999). For a thorough description of the present knowledge on these regions of the magnetosphere, refer to the recently published reviews on the ring current (Daglis et al., 1999) and the inner magnetosphere (Hultqvist et al., 1999).

\subsection{Global magnetosphere modelling}

\subsubsection{Empirical models}

Empirical models for the bow shock and magnetopause have been developed for decades, in the case of the Earth, as well as that of other magnetised planets (e.g. Slavin and Holzer, 1981). Shue et al. (1997) recently published a well documented model, based on fresh data. It has a simple functional form driven by two adjustable parameters: the stand-off distance in the solar direction and the tail flaring.

Empirical models for the magnetic field inside the magnetosphere are based on a statistical analysis of the available magnetic field observations, parameterised by geomagnetic indices. They rely basically on a combination of the Earth's planetary magnetic field - usually described by the IGRF model - and external fields estimated from both in situ magnetic field measurements and mathematical modelling of the current systems (e.g. Tsyganenko, 1990; 1995; Hilmer and Voigt, 1995). These models are updated continuously to account for more and more complex processes in the magnetosphere.

At a given time, the dynamics of the magnetosphere depends on both the present solar wind conditions and magnetosphere status. This status, therefore, depends on the past history of the magnetosphere, and models that only use the present magnetic field values as input cannot provide reliable predictions of the magnetospheric state. In order to develop better predictors, indicators of the magnetosphere history should be added to the inputs.

\subsubsection{MHD simulations}

Fully three-dimensional MHD models of the magnetosphere have already been developed for scientific use. Their input parameters are typically solar wind density, velocity, and interplanetary magnetic field. The inner boundary of the magnetosphere is typically set at somewhat above $3 R_{E}$, and physical quantities are mapped down to the ionosphere along field lines. The output is the dynamic response of the magnetosphere-ionosphere system. These models do not generally provide a proper description of the inner magnetosphere, because of (i) the definition of the inner boundary, and (ii) the presence of dominant non-MHD processes in the inner magnetosphere.

This field is very active. Several groups are developing their own model, and have not yet published their results. The situation is then expected to evolve rapidly during the next decade. The best known global MHD models of the magnetosphere are those developed at the University of Maryland (see Mobarry et al., 1996) and at the University of California at Los Angeles (see Raeder et al., 1997 for a recent application). Another model developed at UCLA (Walker et al., 1993) is worth being mentioned here. In Europe, a model is currently been developed for scientific use only at the Finnish Meteorological Institute (Janhunen, 1996). 


\subsubsection{Kinetic models}

The behaviour of the inner magnetosphere cannot be described in the frame of the MHD approximations ${ }^{4}$. Models of the inner magnetosphere should take into account:

- the non-local character of the plasma response for any transport with characteristic time duration longer than the shorter reflection period;

- the effect of the plasma on the magnetic field;

- the interaction between the different waves in the plasma.

Self-consistent kinetic methods properly describe the fieldparticle interaction and satisfy these requirements at the expense of very heavy calculations. An example of such an approach is the model of substorm growing phases recently developed by Le Contel et al. (1999a, b). Their model is based on the approach proposed by Pellat et al. (1994) and Hurricane et al. (1995) to describe electromagnetic perturbations in a non-adiabatic ${ }^{5}$ plasma. It allows one to estimate the adiabatic response of the plasma to a given external electromagnetic perturbation that originates in the solar wind: an east-west current flowing close to the equatorial plane in the far tail.

The computations could become significantly simpler if one neglects the perturbation generated by the motion of particles, which assumes that the magnetic field model used takes into account satisfactorily the existence of the currents associated with the particles whose motion is studied. This approach uses both an Eulerian approach (global model of the magnetosphere) and a Lagrangian one (particle transport). In practice, it provides an efficient tool for describing the trajectories of the particles in the magnetosphere once an accurate model of the magnetospheric magnetic field, for example, Smets (1998) used such an approach to study the particle distribution functions associated with reconnection processes. Numerical simulation of particle transport then allowed him to characterize particle distributions associated inside the magnetosphere to reconnections at sites with different topology and localisation.

\footnotetext{
${ }^{4}$ The ideal MHD basically assumes that the plasma is a perfectly conductive medium.

${ }^{5}$ Adiabatic responses of a plasma correspond to situations where the motion invariants defined in the frame of the Hamiltonian mechanics are conserved. For a charged particle in the presence of a magnetic field, the first invariant is its magnetic moment $\mu$, the second invariant is the integral along the field line of the component along the magnetic field of the particle momentum, and the third one is the magnetic flux encircled by the particle's periodic drift shell orbits.
}

4.2 Specific models

\subsubsection{The Magnetospheric Specification and Forecast Model (MSFM)}

The MSFM (Freeman et al., 1994; Lambour et al., 1997) is a large-scale physical model designed to specify fluxes of electrons, $\mathrm{H}^{+}$, and $\mathrm{O}^{+}$in the energy range responsible for spacecraft charging, $\sim 100 \mathrm{eV}$ to $\sim 100 \mathrm{keV}$. It is being developed for operational use by the US Air Force, and it is probably, at present, the closest to being an operational large-scale physical model. Its description is available on the net ${ }^{6}$. It is an update of a series of earlier models. Its predecessor, the MSM (Magnetospheric Specification Model), is routinely used by NOAA/SEC for space weather services. Its major improvement compared to the earlier models, is the complexity of the electric and magnetic field models and its capability to run in real time.

The primary input parameters for MSFM are:

1. the $K_{p}$ and $D_{s t}$ geomagnetic indices;

2. the polar cap potential drop and the auroral boundary index that specify the polar ionospheric electric field distribution and the auroral precipitation pattern;

3. the solar wind density and speed, and the interplanetary magnetic field (IMF).

Secondary input parameters include:

1. the sum of $K_{p}$;

2. precipitating particle flux and polar cap potential profiles from the operational DSMP satellites.

The solar wind density and speed define the magnetopause stand-off distance, and the IMF is used to select the appropriate convection pattern in the polar cap. All together, the primary input parameters determine the electric and magnetic field models used. The sum of $K_{p}$ is used as an indicator of the long-term activity level.

The model can operate with reduced sets of input parameters, and in particular, with $K_{p}$ alone. It also includes neural network algorithms that predict the input parameters from solar wind measurements. Thus, it has some capability for short-term space weather forecasting.

MSFM follows particle drift through the magnetosphere using slowly time-varying electric and magnetic field models. The electric and magnetic field configurations are updated every $15 \mathrm{~min}$. The particle distribution is isotropic, and the model keeps track of energetic particle loss by charge exchange and electron precipitation into the ionosphere.

MSFM successfully accounts for most major electron flux enhancements observed at geosynchronous orbit. Flux dropouts that often precede the flux enhancements are predicted with less confidence, and they are often missed near the dawn meridian.

\footnotetext{
${ }^{6}$ http://rigel.rice.edu $\sim$ ding/msfm $95 / \mathrm{msfm} . \mathrm{html}$
} 


\subsubsection{Ring current models}

It has already been mentioned that the ring current composition and dynamic particles is driven by the level of the magnetospheric activity. During periods of magnetospheric activity, the ring current dynamics is driven by particle injection: direct ionospheric ion injection, inward transport of plasma sheet and pre-existing ring current particles. On the contrary, the behaviour of the quiescent ring current is driven by diffusion of low energy protons in the presence of convection electric fields (see, e.g. Daglis et al., 1999). Different quantitative models have been developed accordingly for storm- and quiet-time ring currents.

A family of storm-time ring current models neglects direct injection of ions from the ionosphere. The main source of ring current particles is then the plasma sheet, and the characteristics of that source enter the models as boundary conditions. At least four groups are working at present along this path. They are located at the University of Michigan, the Aerospace Corporation, NASA-Goddard Space Flight Centre, and Rice University (see Chen et al., 1994 for a review of these works). Differences between their models are mainly related to a different selection of aspects of the problem that are treated at a state-of-the-art level or neglected. One of the main difficulties for these models in the context of space weather operational use is the specification of the boundary condition (i.e. the distribution function of the particles at all parts of the boundary, where the drift velocity is inward) in absence of adequate real-time data.

More sophisticated simulations have been developed, which involve both global magnetospheric models and Lagrangian models of particle transport. They have been developed to address questions in relation to academic research rather than to space weather activities. Such a coupled investigation is, however, very promising for space weather activities, since it provides an efficient tool for the particle distribution function determination in a given region of the magnetosphere.

With the objective of analysing the ring current dynamics, Fok et al. (1993) have developed a kinetic model that simulates the evolution with time of the distribution functions for the dominant ions $\left(\mathrm{H}^{+}, \mathrm{He}^{++}, \mathrm{O}^{+}\right)$, as a result of charge exchange and Coulomb collisions. Their results show that during the recovery phase of a magnetic storm, Coulomb collisions lead to generation of low energy $(<500 \mathrm{eV})$ ions and significant heating of plasmaspheric populations. More recently, the model of Fok et al. (1993) and the particle code of Delcourt et al. (1990a) have been coupled to investigate the ring current response to the field line depolarisation observed in the inner magnetosphere during the substorm growing phase. The code of Delcourt et al. (1990a) computes the path of charged single particles, given time-varying electric and magnetic fields, from their injection in the magnetosphere - from the magnetosheath or the ionosphere - to their input in the plasmasphere.

In a more recent study, Fok et al. (1999a) used the particle code of Delcourt et al. (1990b) to estimate the particle distribution in the near tail (at a geocentric distance of about $12 R_{E}$ ), by means of back propagation of particles to their sources. The transport and acceleration of these ions in the inner magnetosphere, as well as their contribution to the ring current, are then computed using the kinetic model of Fok et al. (1993), with a magnetic field more realistic than a dipolar one. These simulations account for many characteristic features of substorms. Further refinements of these investigations will involve an estimate of the initial particle distribution functions from the results of MHD simulations (see, e.g. Fok et al., 1999b) for given solar wind situations, instead of semi-empirical modelling.

Understanding the loss process in the region where the hot ring current plasma coexists with cold plasmaspheric plasma requires modelling of the interaction between ring current ions and plasma waves resonantly generated by the coexisting hot and cold plasmas. Modelling wave particle interaction on a global scale is very challenging because it needs a self-consistent description of wave and particle behaviour.

\subsubsection{Radiation belt models}

\subsubsection{Empirical models}

Very early in the space era, it became clear that the average radiation doses received by satellites are key parameters that should be known. The United States and the former Soviet Union, therefore, started building empirical models of radiation belts, using data collected for several years on board a number of satellites.

In the United States, these models were developed for NASA by Aerospace Corporation. The latest versions are the AP8 (Aerospace Protons \#8) and AE8 (Aerospace Protons \#8) models (Sawyer and Vette, 1976; Vette, 1991). They have been built at the end of the 1970s, using data from about 40 satellites that were in orbit between 1961 and 1977, a period that mostly corresponds to solar cycle \#20. They provide proton flux for energy in the range $100 \mathrm{keV}$ to $400 \mathrm{MeV}$ and electron flux for energy in the range $40 \mathrm{keV}$ to $7 \mathrm{MeV}$, for altitudes up to that of geostationary orbits.

The necessity of updating these models led the United States to launch a satellite dedicated to radiation measurements: the NASA/DoD CRRES (Combined Release and Radiation Effect Satellite) satellite. It has been operational for 14 months - between August 1990 and October 1991 - that roughly corresponds to the maximum of solar cycle \# 22 . The CRRES data have been used by DoD to develop new empirical models for the proton (CRRESPRO) and electron (CRRESELE) radiation belts (see, e.g. Brautigham et al., 1992; Gussenhoven et al., 1993). These models do not provide a significant updating of earlier models, because (i) the altitude and energy ranges they cover are not as wide as those covered by NASA's AP and AE models, and (ii) they rely on data collected by only one satellite during a disturbed period that is probably not representative of the average behaviour of the radiation belts. 
On the contrary, the durability of some meteorological satellites gives the opportunity to improve the models for the low altitude range. Boeing is presently preparing for NASA a model using the NOAA/TIROS satellite data (Huston et al., 1998). This model relies on measurements made since 1978 , i.e. over almost two solar cycles. Despite its limitation with respect to altitude $(<800 \mathrm{~km})$ and energy ( 3 ranges for energy larger than $16 \mathrm{MeV})$, it is a significant improvement compared to earlier models because it describes the evolution with solar cycle of high energy proton fluxes. The authors are now trying to extend the altitude range addressed by the model.

In addition to the models described above, nucleus of models appear at many places in the world. Most of them rely on data from only one satellite, and their representativeness is limited accordingly. As a result of these limitations, the AP8 and AE8 empirical models will probably still remain the standard to be used for mission planning during the next few years, despite their own limitations.

\subsubsection{Physical models}

Physical models have also been developed very early, in order to elucidate the radiation belt sources and their dynamics. Due to the limitation in the computer capacities, they did not significantly evolve during the 1980s. The increasing efficiency of computers allowed one to restart their development at the beginning of the 1990s. During the last few years, they allowed us to make possible significant breakthroughs in our understanding of the sources and dynamics of the proton and electron belts.

They rely basically on the resolution of the Fokker-Planck diffusion equation in adiabatic conditions. They take into account more and more different physical phenomenon:

- particle-particle interactions;

- wave-particle interactions;

- Coulomb interactions;

- plasma influence.

An example of such code is Salammbô, a set of codes devoted to the understanding of high energy charged particle transport in the inner part of the magnetosphere, in particular during magnetic activity periods. The first one, called Salammbô-3D, solves the classical Fokker-Planck diffusion equation, either for proton or electron radiation belts, in the 3 -D phase space. The equation is classically written in terms of the three adiabatic invariant, corresponding to energy, pitch angle and $L$ Mcllwain parameter, so this version is a real 2-D one in space, where the results are averaged with respect to the longitude (local time) (Beutier et al., 1995; Beutier and Boscher, 1995). The Salammbô-4D version is an extended version of Salammbô-3D, taking into account the longitude (local time), so it is a real 3-D one in space. It was developed to understand injections during substorm periods, and their effects, such as drift echoes or the growth of the ring current. In this version, it is possible to follow particles in their drift around the Earth (Bourdarie et al., 1997).

Tests made on the prediction of the time dependence of the lifetime of trapped electrons (i.e. the time needed to have the initial flux decreased by a factor $e$ ) have shown that radiation belt models are very sensitive to the waves (Baussart et al., 2000). The elaboration of a physical radiation belt model, therefore, requires the introduction of a wave model. The two models presently used are the Abel and Thorne semi-empirical model (Abel and Thorne, 1998a, b) and the LPCE/CEA empirical model (Baussart et al., 2000; Lefeuvre et al., 2000) based mainly on statistics performed from 3 years of DE-1 data and on wave normal directions estimated from GEOS-1 and ISEE-1 data.

\section{The ionosphere-thermosphere system}

Above $90 \mathrm{~km}$ altitude, the upper thermosphere is characterized by a large density decrease, that implies a decrease in the collision frequency between molecules. The temperature increases rapidly from about $180 \mathrm{~K}$ to the thermopause value of about $1000 \mathrm{~K}$. This value, constant above $300 \mathrm{~km}$, is also called the exospheric temperature. It is directly dependent on the solar energy in the UV and EUV bands and on the auroral energy inputs. The main atmospheric constituents, nitrogen and molecular oxygen, are dissociated and ionised by the absorption of EUV solar radiation and particle precipitation to form the ionosphere. The resulting ionised species are mainly molecular ions $\left(\mathrm{N}_{2}^{+}\right.$and $\mathrm{O}_{2}^{+}$) at low altitude (below $200 \mathrm{~km}$ ) and atomic ions $\left(\mathrm{O}^{+}\right)$at high altitude (above $200 \mathrm{~km}) . \mathrm{N}^{+}$is created by $\mathrm{N}_{2}$ dissociative ionisation, $\mathrm{H}^{+}$ by charge exchange reactions between $\mathrm{O}^{+}$and $\mathrm{H}$. Finally, $\mathrm{NO}^{+}$arises from chemical recombination with neutrals. It is a major ion of the E-region, although its neutral parent NO is a minor constituent of the atmosphere in that region. The ionosphere can, therefore, be said to be composed of three molecular ions $\left(\mathrm{N}_{2}^{+}, \mathrm{NO}^{+}\right.$and $\left.\mathrm{O}_{2}^{+}\right)$, three atomic ions $\left(\mathrm{H}^{+}\right.$, $\mathrm{N}^{+}$and $\mathrm{O}^{+}$) and electrons. The altitude of the maximum of the electron density is close to $250 \mathrm{~km}$.

The understanding of the behaviour of this solar-terrestrial sub-system and its effects on technological operations is determined by the ability to model at least the height, geographical and time distributions of the electron concentration and the neutral densities. The modelling effort has started a long time ago, due to the development of our technological society (telecommunications, orbitography, etc.). However, there is no numerical code or model that is able at the present time to describe accurately both the three-dimensional and time-dependent distribution of the ionospheric plasma, and the thermospheric densities during quiet and disturbed conditions. In other words, no model is able to reproduce in a satisfactory way both the climate and the weather of the Earth's ionosphere-thermosphere. In addition, there is no well established experimental database that can be used to verify and test the existing models, in order to generate the improvements needed. 
At present, most models are able only to reproduce consistently the climate of the ionosphere and the thermosphere, as defined mostly by diurnal, seasonal and solar cycle variations. Serious theoretical and computational efforts, supported by complex combinations of experimental techniques, are being done to model and predict the weather. This weather is defined as the hour-to-hour, day-to-day, week-toweek variability of the electron and neutral concentrations within the framework of the climatology.

Three different types of models can be identified, each of them having implicit limitations and advantages:

- semi-empirical and empirical models;

- physical models;

- in the case of ionospheric modelling only, analytical "profilers" based on routinely scaled ionospheric data.

The physical models of the ionosphere and the thermosphere use as inputs results from empirical models of the convection electric field and auroral precipitations, in order to describe the coupling with the magnetosphere. Such models are also presented at the end of this section.

\subsection{Empirical and semi-empirical models}

\subsubsection{Ionospheric models}

These models are based on a description of the ionosphere in terms of analytical functions. These functions are estimated either from experimental data or from the results of physical models.

A well-known empirical model widely used for different applications is the International Reference Ionosphere (IRI) ${ }^{7}$ (Bilitza, 1990). This is the result of an international project sponsored by the Committee on Space Research (COSPAR) and the International Union of Radio Science (URSI), which aimed at producing a reference model of the ionosphere based on available experimental data sources. For a given location, time and date, IRI describes the electron concentration, electron temperature, ion temperature, and ion composition in the altitude range from about $50 \mathrm{~km}$ to about $2000 \mathrm{~km}$, as well as the total electron content (TEC). The solar activity is represented by the sunspot number index. IRI provides monthly averages in the non-auroral ionosphere for magnetically quiet conditions; it can also be used for estimating the profile of electron concentration using the experimental values of $\mathrm{F} 2$ peak electron concentration (i.e. $f o \mathrm{~F} 2$ ) and height as inputs.

The major IRI data sources are the coefficients $(f o \mathrm{~F} 2$ and $\mathrm{M}(3000)$ ) produced by the Radiocommunication Sector of the International Telecommunication Union (ITU-R) ${ }^{8}$ on the basis of a large set of ground vertical ionosonde data, the

\footnotetext{
${ }^{7}$ Available on the NSSDC site: http://nssdc.gsfc.nasa.gov/space/ model/models_home.html

${ }^{8}$ http://www.itu.int/ITU-R/index.html
}

powerful incoherent scatter radars (Jicamarca, Arecibo, Millstone Hill, Malvern, St. Santin), the ISIS and Alouette topside sounders, and in situ instruments on several satellites and rockets. IRI is updated periodically and has evolved over a number of years.

At present, the major limitation of IRI appears to be its description of the electron distribution in the region above the peak of the F2-region (topside ionosphere). Such distribution gives vertical total electron contents that have values above the expected ones, particularly at middle and high latitudes for high solar activity. The height limit of $2000 \mathrm{~km}$ for the electron concentration calculation is a major limit for the use of IRI to provide TEC estimates for satellite heights, such as those of the GPS constellation.

A group of semi-empirical models have been developed by D. N. Anderson and colleagues of the Phillips Laboratory of the USAF. There are based on the combination of databases of coefficients that reproduce theoretically calculated profiles based on physical models:

- the Semi-Empirical Low-Latitude Ionospheric Model (SLIM) (Anderson et al., 1987) is based on a theoretical simulation of the low-latitude ionosphere. Electron concentration profiles are determined for different latitudes and local times by solving the continuity equation for $\mathrm{O}^{+}$ions. The profiles are normalised to the $\mathrm{F}$ 2-peak concentration and are then represented by a Modified Chapman function using six coefficients per individual profiles. Input parameters used in the theoretical calculation include the MSIS model neutral temperatures and densities (see below), the IRI model temperature ratios, and the diurnal ion drift patterns observed by the Jicamarca incoherent scatter radar for the different seasons;

- the Fully Analytical Ionospheric Model (FAIM) (Anderson et al., 1989) uses the formalism of the Chiu model (Chiu, 1975) with coefficients fitted to the SLIM model profiles. The local time variation is expressed by a Fourier series up to order 6 , and the variation with dip latitude by a fourth order harmonic oscillator function (Hermite polynomial);

- the same group developed a Parameterised Real-time Ionospheric Specification Model (PRISM) (Daniell et al., 1995) that consists of two segments. One is the Parameterised Ionospheric Model (PIM) and the other incorporates near-real-time data from ground and satellite sensors. PIM is a relatively fast global ionospheric model. It is based on the output of physical ionospheric models developed by the Utah State University and Boston College. It consists of a source code and a large database of runs of ionospheric specification codes. From a given set of geophysical conditions (day of the year, solar activity index $f_{10.7}$, geomagnetic activity index $K_{p} \ldots$ ) and positions (latitude, longitude, and altitude), the model can produce critical frequencies and peak heights for the ionospheric E- and 
F2-regions, as well as electron concentration profiles from 90 to $1600 \mathrm{~km}$ and TEC.

\subsubsection{Thermospheric models}

Thermospheric semi-empirical models are based on the hypothesis of independent static diffusive equilibrium of the different thermospheric constituents above $120 \mathrm{~km}$ altitude. The density of each constituent decreases exponentially with altitude, according to its own scale height that depends on its mass and on the temperature. The temperature variation is described by the Bates profile that is a function of the exospheric temperature, and the temperature and its gradient at the lower limit. The temperature and the gas concentration evolve depending on season and solar local time, latitude, solar flux represented by the $f_{10.7}$ index, and magnetic activity represented by $A_{p}$ or $K_{p}$ indices. Periodic functions are used to represent the diurnal and seasonal variations. Latitudinal, solar activity and magnetic activity variations are represented by non-periodic functions that may differ from one model to another.

The DTM-78 model (Drag Temperature Model; Barlier et al., 1978) has been developed at the Centre d'Etudes et de Recherches Geodynamiques (CERGA, France) in a cooperative effort with the Institut d'Aéronomie spatiale in Belgium and the Service d'Aéronomie du CNRS in France. It is based on temperature measurements by the OGO-6 satellite and density data from drag observations. The DTM-94 version (Berger et al., 1998) include data from the microaccelerometer CACTUS (1975-1979) and from the Dynamic Explorer 2 satellite (1981-1983). This version is actually used for various applications: trajectory computation for satellites such as SPOT or TOPEX/POSEIDON and developments of gravity models. A new version is under development by CNES/GRGS and Service d'Aéronomie, in order to better describe the variations in the lowest altitude region (120 to $150 \mathrm{~km})$.

MSIS (Mass Spectrometer and Incoherent Scatter) is the most widely used model in the scientific community. It has been developed by GSFC (Goddard, Maryland) and is based on satellite mass spectrometer data and ground incoherent scatter data. The MSIS-86 version (Hedin, 1987) became the highest part (altitude above $90 \mathrm{~km}$ ) of the COSPAR International Reference Atmosphere (CIRA). The MSISE-90 version ${ }^{9}$ (MSIS Extented, Hedin, 1991) describes the atmosphere from the ground level. Above $72.5 \mathrm{~km}$ altitude, it is a revised version of MSIS- 86 that includes new data. Above $120 \mathrm{~km}$, MSIS- 86 and MSISE-90 are identical.

An empirical model of the thermospheric winds has also been developed by GSFC. The first version, HWM-87 (Horizontal Wind Model), is based on data from the AE-E and DE-2 satellites. Ground-based measurements by incoherent scatter radars and Fabry-Perot interferometers have been added in the version HWM-90 (Hedin et al., 1991) to lower

\footnotetext{
${ }^{9}$ Avalaible on the NSSDC site: http://nssdc.gsfc.nasa.gov/space/ model/models_home.html
}

the altitude limit down to $100 \mathrm{~km}$. The last version HWM$93^{10}$ (Hedin et al., 1996) describes the winds almost from the ground using data from MF and meteor radars.

The MSIS and HWM models are often used as inputs for physical modelling, for example, the ionospheric and radiation belt models. MSISE-90 will be used for orbit prediction of the TIMED spacecraft. Current development efforts have been transferred at NRL (Washington, D. C.) and are focused on the improvement of the solar and geomagnetic input specifications, and on the incorporation of new data sources (Picone et al., 2000).

\subsection{Physical models}

The macroscopic behaviour of the ionospheric molecular ions $\left(\mathrm{N}_{2}^{+}, \mathrm{NO}^{+}\right.$and $\left.\mathrm{O}_{2}^{+}\right)$and atomic ions $\left(\mathrm{H}^{+}, \mathrm{N}^{+}\right.$and $\mathrm{O}^{+}$) is described through the "fluid approach". The set of transport equations (continuity, momentum, energy and heat flow) corresponding to this approach is derived from Schunk (1977). It solves the temporal evolution of the concentration, the field-aligned velocity, and the temperature and the fieldaligned heat flow of each species.

On the other hand, precipitating electrons or primary photoelectrons move along the magnetic field lines, producing heat, excitation and ionisation. A cascade may occur, producing secondary electrons through electron impact collisions. These microscopic collisions and absorption are described through a kinetic approach. Some outputs of the kinetic equation are the ion and electron productions, and the thermal electron gas heating rate.

Therefore, a physical description of the ionosphere requires the coupling of the two approaches. Global or limited area models that use basic physical principles controlling the ionospheric plasma have been developed in recent years. They make use of empirically specified input data. The main ones are the solar EUV/UV radiation (see Sect. 5.5), the ion convection pattern (see Sect. 5.4) and the auroral precipitation pattern (see Sect. 5.4). The accuracy of these inputs limits the ability of these physical models to reproduce climatic and space weather conditions. One finds in Schunk (1996) an extensive review on the situation up to 1996. In 2002, the main ionospheric models that follow this approach are the Utah State University model of the global ionosphere (Schunk and Sojka, 1996), the University of Alabama Field Line Integrated Plasma (FLIP; Richards and Torr, 1996), the Phillips Laboratory Global Theoretical Ionospheric Model (GTIM; Anderson et al., 1996), and the TRANSCAR model (Lilensten and Blelly, 2002). Zhang et al. (1993) and Zhang and Radicella (1993) developed a time dependent ionospheric model essentially limited to middle latitudes, but with the advantage of being fast in comparison with global model calculations.

All of these models are suitable for the investigation of the influence of different physical processes on the ionosphere.

\footnotetext{
${ }^{10}$ Avalaible on the NSSDC site: http://nssdc.gsfc.nasa.gov/space/ model/models_home.html
} 
Their main outputs are the electron concentration distribution, electron and ion temperatures, ion velocity, with all parameters measurable by incoherent scatter radar. There are several other outputs, such as electron heating rate, ion and electron production, or ion and neutral excitation rates. From this last parameter, it is possible to compute the electromagnetic emissions due to the deactivation. As an example, Witasse et al. (1999) have added the calculation of the thermospheric red and green oxygen emission lines, in order to use TRANSCAR as a diagnostic tool for the thermosphere.

The physical description of the upper atmosphere requires the need to raise the question of the ionospherethermosphere coupling, and possibly the coupling with the lower atmosphere. Coupled approaches necessitate solving self-consistently the 3-D time-dependent equations of momentum, energy and continuity for neutral particles and ions. Parameters relevant to the ion-neutral and neutral-ion coupling are exchanged at every few time steps between the thermospheric and ionospheric codes.

The Coupled Thermosphere-Ionosphere-Plasmasphere or CTIP (Fuller-Rowell et al., 1996; Millward et al., 1996) is one of the most comprehensive upper atmosphere models currently available. It covers the region from $80 \mathrm{~km}$ to $450 \mathrm{~km}$ altitude in the neutral atmosphere, $120 \mathrm{~km}$ to $10000 \mathrm{~km}$ in the ionosphere. This model has been used extensively to study the response of the ionosphere/thermosphere system to geomagnetic storms (Codrescu et al., 1997; Fuller-Rowell et al., 2000). In 1998, it was used in the frame of space weather in an effort to set a network for ionospheric predictions (Szuszczewicz et al., 1998). Different recent code developments have been performed. They include the addition of tidal and planetary wave forcing at the CTIP model's lower boundary (FullerRowell et al., 1999; Muller-Wodarg et al., 2000); selfconsistent calculation of the E-region dynamo electric field (Millward et al., 2000); flexible high-latitude auroral precipitation and convection electric field (Schoendorf et al., 1996), including the proton precipitation (Galand et al., 2001); and extension of the lower boundary below the stratopause down to $30 \mathrm{~km}$ (Harris, 2000, personal communication).

The NCAR TGCM's are three-dimensional, timedependent models of the Earth's neutral upper atmosphere (Roble and Ridley, 1994 and references herein). Recent models in the series include a self-consistent aeronomic scheme for the coupled Thermosphere/Ionosphere system, the Thermosphere Ionosphere Electrodynamic General Circulation Model (TIEGCM), and an extension of the lower boundary from 97 to $30 \mathrm{~km}$, including the physical and chemical processes appropriate for the mesosphere and upper stratosphere, the Thermosphere Ionosphere Mesosphere Electrodynamic General Circulation Model (TIME-GCM). The outputs of the TIME-GCM consist of 30 neutral atmospheric parameters on a three-dimensional latitude, longitude, pressure grid. Geographic longitude begins at $-180^{\circ}$ west and continues around the globe with a $5^{\circ}$ resolution. Geographic latitude resolution is also $5^{\circ}$, from -87.5 south to +87.5 north. The vertical dimension is in a log pressure scale from -17.0 at the bottom (approximately $30 \mathrm{~km}$ ) to 5.0 at the top (varying in altitude up to about $400 \mathrm{~km}$ ). The applications are numerous, and a very large number of papers have been published in the past years based on the use of this model and comparison with experimental data. Recent applications include a comprehensive study of the atmospheric tides (Hagan and Roble, 2002).

The next step in the physical description of the upper atmosphere is to couple the TIE codes with the upper boundary conditions, i.e. magnetospheric/protonospheric codes. This has been achieved for the first time by the numerical model of the Earth's upper atmosphere (Namgaladze et al., 1991) constructed at the Kaliningrad Observatory of IZMIRAN and at the Polar Geophysical Institute in Murmansk. This model covers the height range from $80 \mathrm{~km}$ up to a geocentric distance of 15 Earth radii. It consists of three main blocks: thermospheric, ionospheric-protonospheric and an electric field computation block. The exchange of information between these blocks is carried out at every time step of the numerical integration of the modelling equations (typically $2 \mathrm{~min}$ ). The electric fields, both of thermospheric dynamo and magnetospheric origin, and protonospheric parameters are calculated consistently. For the thermospheric and molecular ion parameters, the latitudinal integration steps vary from $10^{\circ}$ at the geomagnetic equator to $2^{\circ}$ at the auroral zones. For the electric field, ionospheric F2-region and protonospheric parameters, they vary, respectively, from $5^{\circ}$ to $2^{\circ}$. The longitude step is $15^{\circ}$. The thermosphere is computed between 80 and $520 \mathrm{~km}$ at 30 altitude levels. This model has been used in several applications. Recently, the effect of geomagnetic storms on both the thermosphere (Förster et al., 1999) and the ionosphere (Namgaladze et al., 2000) have been investigated.

The Magnetosphere-Thermosphere-Ionosphere-Electrodynamics-General circulation model (MTIE-GCM; Peymirat et al., 1998) couples the TIE-GCM (Richmond et al., 1992) and the Ionosphere-Magnetosphere model of Peymirat and Fontaine (1994). It calculates self-consistently the 3-D structure of the thermosphere and of the ionosphere, the 2-D structure of the magnetospheric plasma convection in the equatorial plane of the magnetosphere, and the couplings between the thermosphere, the ionosphere and the magnetosphere. Once given as inputs, the distribution of the electric potential along the polar cap boundary, and the density and temperature of the magnetospheric plasma source, the magnetospheric part computes the motion of the magnetospheric plasma, from which it deduces the auroral precipitation and the region's two field-aligned currents. These are transmitted to the TIE-GCM part, which computes the 3-D dynamics of the thermosphere and ionosphere. The ionospheric electric field is also computed considering the effect of auroral precipitation, the effect of the region's two field-aligned currents and the effect of the neutral winds. The ionospheric electric field is then transmitted to the magnetospheric part, in order to calculate the motion of the magnetospheric plasma. This model is used to evaluate the feedback coupling among the magnetosphere-ionosphere- 
thermosphere system and specifically to check the influence of the neutral winds on this coupling. A coupling of the magnetospheric part to the physical ionospheric code TRANCAR, described above, is under way (Peymirat and Blelly, personal communication, 2001).

\subsection{Ionospheric profilers}

Another way to estimate the electron concentration distribution with height is based on data assimilation techniques. It is based on adjustments of a parameterised profile, expressed in terms of simple mathematical functions, to ionospheric characteristics routinely scaled from the ionograms. The advantage of this type of "profile modelling" is that it can, in principle, use as inputs experimental values of basic ionospheric characteristics for both quiet and disturbed conditions. The so-called "profilers" share with the other types of models the difficulty of describing well the topside ionosphere. This is essentially due to the absence of a well-established experimental database of topside profiles, which is necessary to obtain a clear description of the topside ionosphere behaviour.

The Bradley and Dudeney (1973) "profiler" describes the electron concentration profile up to the peak of the F2-region. It consists of two parabolic layers for the E- and F2-layer and a linear segment in between. This profile generation is still used by the ITU-R HF propagation prediction method. Dudeney (1978) has later proposed a more refined profile that uses routinely scaled characteristics, incorporates combinations of trigonometric-function segments, and provides optional valley and an F1-ledge description. The main advantage of this profile over the previous one is the continuity of the gradient of electron concentration with height across the segment boundaries.

The DGR model, a "profiler" originally introduced by Di Giovanni and Radicella (1990) and improved by Radicella and Zhang (1995), is able to describe the electron concentration profile in the E, F1, F2-regions of the ionosphere by using simple analytical expressions. It is essentially based on the Epstein layer introduced by Rawer (1982) and considers the existence of characteristic points in the profile with coordinates (values of electron concentrations and their height) calculated by means of empirical expressions. The model is constructed as the sum of three Epstein layers that are formally identical. The model calculates the electron concentration profile above the $\mathrm{F} 2$ peak, making use of an effective shape parameter empirically derived for the topside ionosphere. The total electron content is computed with an analytical expression obtained from the Epstein layers formulation of the model. This model of electron concentration profile has been adopted by the European Commission COST 238 (PRIME) action and it is part of the computer program produced by the action.

A new family of electron concentration "profilers", which differ in complexity and which have different but related application areas, has been developed (Hochegger et al., 2000). They are based on the DGR "profiler" concept and also allow for the use of median or instantaneous values, or maps based on regional or global experimental data. The three models are:

- NeQuick is a quick-run model for ionospheric applications. This model has been adopted in the ionospheric specifications for the European Space Agency EGNOS project;

- COSTprof is a model that can be used for ionospheric and plasmaspheric satellite to ground applications. This model has been adopted by the COST 251 action of the European Commission as the profiler for its electron concentration distribution;

- NeUoG-plas is a model that can be used particularly in assessment studies involving satellite to satellite propagation of radio waves.

The basic input parameters are values $f_{\circ} \mathrm{F} 2$ and $\mathrm{M}(3000) \mathrm{F} 2$. The output of the models is the electron concentration in the ionosphere as a function of height, geographic latitude and longitude, solar activity (given by sunspot number or by $10.7 \mathrm{~cm}$ solar radio flux), season (month) and time (Universal Time UT or local time LT). The models also permit one to calculate electron concentration along arbitrarily chosen ray paths and slant, or vertical total electron content up to heights in the plasmasphere, such as those of GPS satellites. The profiles are continuous in all spatial first derivatives (a necessity in applications like ray tracing and location finding).

Above $100 \mathrm{~km}$ and up to the F2-layer peak, all three models are identical using a modified DGR formulation. They use the ITU-R coefficients for $f o \mathrm{~F} 2$ and $\mathrm{M}(3000) \mathrm{F} 2$, and simplified models for $f o \mathrm{~F} 1$ and $f o \mathrm{E}$, which take into account solar zenith angle, season and solar activity. The topside F-layer for the NeQuick model is again a semi-Epstein layer, but with a height dependent thickness parameter (Radicella and Zhang, 1995). For the COSTprof, the topside ionosphere formulation uses three physical parameters, namely the oxygen scale height at the F2 peak, its height gradient, and the $\mathrm{O}^{+}$ $-\mathrm{H}^{+}$transition height. These three parameters are modelled according to solar activity, season, local geographic latitude, and "modified dip latitude". NeUoG-plas has an additional geomagnetic field-aligned third part for the "plasmasphere" to model this region in a more realistic way.

\subsection{Convection electric field and auroral precipitation models}

Such empirical models are used as inputs of the physical ionospheric and coupled ionospheric thermospheric 3-D models. Only the most recent and well-known models are presented below.

The Heppner-Maynard-Rich Electric Field Model is a software package ${ }^{11}$ that includes several empirical electric convection field models, and the AFGL Precipitation and

\footnotetext{
${ }^{11}$ Avalaible on the NSSDC site: http://nssdc.gsfc.nasa.gov/space/ model/models_home.html
} 
Conductivity Model; the latter for obtaining conductances, currents, and heating. The Heppner-Maynard models are based on OGO 6 and DE 2 electric field measurements and provide the electric potential and field poleward of $60^{\circ}$ geomagnetic latitude (Heppner and Maynard, 1987). Seven different models were generated for different Interplanetary Magnetic Field (IMF) conditions. Spherical harmonics to order 11 in magnetic local time and latitude are used in each case. For southward IMF, an explicit variability with geomagnetic activity is included. The Heelis Electric Convection Field Model (Heelis et al., 1982) is included in this package for comparative purposes. Rich and Maynard (1989) illustrate the improvements of their model in relation to the Heelis model and point out the differences to the Millstone Hill Electric Field Model (Holt et al., 1987) in the region of the Harang discontinuity and near the dayside cleft.

Based on the same set of satellite data, the UAF Eulerian Polar Ionosphere Model (Weimer, 1996) is formulated in the corotating frame and has a scaleable horizontal resolution (up to $100 \times 100 \mathrm{~km}$ ). It derives the electric potentials in the high-latitude ionosphere, resulting from any arbitrary combination of the IMF magnitude and orientation, solar wind velocity, and dipole tilt angle. It is currently used to prepare ionospheric convection maps.

The Izmiran Electrodynamic Model (IZMEM, Feldstein et al., 1984) is based on the inversion of geomagnetic groundbased observations. The 1985 version is parameterized by the interplanetary magnetic field (IMF) strength and direction and is available for the three seasons (summer, winter, equinox). Seven parameters of the high-latitude ionospheric electrodynamics can be determined for the specific IMF strength and orientation $\left(B_{x}, B_{y}, B_{z}\right)$ : geomagnetic perturbation vectors at the Earth's surface, electrostatic field potential at the ionospheric altitude, as well as electric field vectors, field-aligned currents, ionospheric current vectors, equivalent current vectors, and Joule heating rate. The new IZMEM/DMSP ${ }^{12}$ model produces patterns obtained after recalibration of the IZMEM model by the observed DMSP electrostatic potentials (Papitashvili and Rich, 2002). It uses real-time IMF data from the ACE satellite.

The AFGL Electron Precipitation Model (Hardy et al., 1987) and the AFGL Ion Precipitation Model (Hardy et al., 1989) provide the integral energy and number flux of precipitating auroral electrons and ions as a function of corrected geomagnetic latitude, magnetic local time, and magnetic activity $\left(K_{p}\right)$. These are based on millions of spectra from the DMSP-F2, F4, F6, and F7 satellites and the P78-1 satellite. At each level of activity, the high-latitude region was separated into 30 zones in corrected geomagnetic latitude (from $50^{\circ}$ to $90^{\circ}$ ) and 48 one-half-hour zones in magnetic local time. The electron model also provides Pedersen and Hall conductivities, using empirical relationships between conductivities, electron energy flux, and average energy.

For space weather applications, it should be noted that real-time global convection maps, or the equivalent electro-

\footnotetext{
${ }^{12} \mathrm{http} / / /$ www.sprl.umich.edu/MIST/spw.html
}

static potential maps, constrained by SuperDARN radar measurements, have recently been made avalaible ${ }^{13}$ (Shepherd and Rhuohoniemi, 2000). Convection pattern and the auroral precipitation pattern can also be deduced from all available data (geomagnetic and radar ground-based observations and in situ measurement of electric field and auroral precipitation) using the AMIE procedure (Richmond, 1992) which today is not a real-time procedure. The use of such time dependant auroral inputs has dramatically increased the physical model's reliability for describing the ionosphere and thermosphere during disturbed conditions.

\section{$5.5 \mathrm{EUV} / \mathrm{UV}$ models for aeronomy}

The ultraviolet (UV)/extreme ultraviolet (EUV) solar flux is energetic enough to ionize the upper atmosphere. It constitutes the major source for the diurnal ionosphere. Most of the current models rely on a few experiments taken on board the Dynamics Explorer missions (Hinteregger et al., 1973). A first representation of solar EUV fluxes for aeronomical applications was given by Hinteregger (1981), and Hinteregger and Katsura (1981). A first reference flux SC\#21REF was assembled from measurements performed in July 1976, at a period where $f_{10.7}=70$, and given for 1659 wavelengths. An extrapolation model (SERF 1) allows one to estimate the flux during other periods of solar activity.

Torr and Torr $(1979,1985)$ proposed two reference fluxes for aeronomy called $\mathrm{F} 79050 \mathrm{~N}$ - corresponding to $f_{10.7}=$ 243 - and SC\#REFW - corresponding to $f_{10.7}=68$. The UV spectrum was divided in 37 bins. Some bins correspond to intense spectral lines, but the bright Lyman $\alpha$ line at $121.565 \mathrm{~nm}$ does not show up because it is not energetic enough to ionise the terrestrial ionosphere. This work proved to be extremely useful. One of its qualities was that the authors proposed the corresponding absorption and ionisation cross sections for the major thermospheric species. Its main limitation is that the measurements do not allow one to reach a good estimate of the flux variability for different solar activity conditions.

Since then, several authors developed their codes in order to take better advantage of the AE database. Amongst them, two are worth noting here:

- Tobiska (Tobiska, 1991; Tobiska and Eparvier, 1998) developed a model called EUV, which takes data from other sources into account: SME, OSO; AEROS; rockets and ground-based facilities. This model takes into account the solar emission zone of each line, through a parameter. It proposes a formula to retrieve a solar flux from the gift of the decimetric index and its average. A new version, SOLAR2000, has been recently developed. It uses a new input parameter named E10.7, computed from a previous version of the code (Tobiska et al., 2000);

- The second improved model is EUVAC (Richards et al., 1994). Its main difference with previous models is

\footnotetext{
${ }^{13} \mathrm{http} / / /$ superdarn.jhuapl.edu/index.html
} 
Table 2. Synthesis of model inputs and outputs of pre-operational and operational models. Only the ones most often used in a given category are indicated. A column indicates if the model is a physical one $(P)$ or a semi-empirical or empirical one $(E)$ and 2 columns state whether development of the model itself or availability of new observations is the most crucial for its improvement

\begin{tabular}{|c|c|c|c|c|c|c|c|c|}
\hline & Models & Based on & Inputs & Outputs & $\begin{array}{l}P \\
\text { or } \\
E\end{array}$ & $\begin{array}{l}\text { Model } \\
\text { develop- } \\
\text { ment } \\
\text { needed }\end{array}$ & $\begin{array}{l}\text { Observations } \\
\text { needed for } \\
\text { improving } \\
\text { the model }\end{array}$ & Remark \\
\hline Sun & Torr & $\begin{array}{c}\mathrm{DE} \\
\text { satellite data }\end{array}$ & $\mathrm{F}_{10.7}$ & $\begin{array}{l}\text { EUV/UV } \\
\text { spectrum }\end{array}$ & $E$ & & $\mathrm{X}$ & $\begin{array}{l}\text { New models under } \\
\text { construction }\end{array}$ \\
\hline \multirow{5}{*}{$\begin{array}{l}\text { Magneto- } \\
\text { sphere }\end{array}$} & Shue et al. & Satellite data & $\begin{array}{c}\text { IMF Bz } \\
\text { Solar wind density } \\
\text { and velocity }\end{array}$ & $\begin{array}{l}\text { magnetopause } \\
\text { size and shape }\end{array}$ & $E$ & & $\mathrm{X}$ & \\
\hline & Tsyganenko & $\begin{array}{c}\text { IGRF } \\
\text { Satellite magnetic } \\
\text { field data }\end{array}$ & $\begin{array}{c}\text { Geomagnetic indices } \\
\text { IMF } \\
\text { Solar wind density } \\
\text { and velocity }\end{array}$ & Magnetic Field & $E$ & & & \\
\hline & MSM & IGRF & $\begin{array}{c}\text { Geomagnetic indices } \\
\text { IMF } \\
\text { Solar wind density } \\
\text { and velocity }\end{array}$ & $\begin{array}{l}\text { Magnetospheric particle } \\
\text { fluxes: } 0.1-100 \mathrm{Kev} \\
\text { Magnetospheric E and B } \\
\text { Precipitating electrons } \\
\text { Ionospheric convection }\end{array}$ & $P$ & & & $\begin{array}{l}\text { Next } \\
\text { generation: } \\
\text { MSFM }\end{array}$ \\
\hline & AP8-AE8 & $\begin{array}{c}\text { Satellite data } \\
\text { from 1960-1975 }\end{array}$ & $\begin{array}{l}\text { Solar activity: } \\
\text { min or max }\end{array}$ & $\begin{array}{c}\text { Particle fluxes } \\
\text { Protons: } 0.1-400 \mathrm{MeV} \\
\text { Electrons: } 0.1-7 \mathrm{MeV}\end{array}$ & E & & $X$ & $\begin{array}{c}\text { Magnetic storm } \\
\text { effects } \\
\text { non included }\end{array}$ \\
\hline & $\begin{array}{l}\text { LPCE/CEA } \\
\text { Wave model }\end{array}$ & $\begin{array}{l}\text { Satellite data: } \\
\text { DE-1 }\end{array}$ & Geomagnetic indices & $\begin{array}{c}\text { Magnetic field power } \\
\text { density spectrum } \\
\text { Wave distribution } \\
\text { Function }\end{array}$ & $E$ & & $X$ & $\begin{array}{l}\text { Presently only } \\
2 \text { Kp classes }\end{array}$ \\
\hline \multirow{6}{*}{$\begin{array}{l}\text { Iono- } \\
\text { sphere }\end{array}$} & $\begin{array}{c}\text { Heppner- } \\
\text { Maynard-Rich }\end{array}$ & Satellite data & $\begin{array}{c}\text { Geomagnetic indices } \\
\text { IMF }\end{array}$ & $\begin{array}{l}\text { Convection } \\
\text { electric field }\end{array}$ & $E$ & & & \\
\hline & SuperDARN & $\begin{array}{c}\text { Radar data } \\
\text { assimilation }\end{array}$ & $\begin{array}{c}\text { IMF } \\
\text { SuperDARN radar data }\end{array}$ & $\begin{array}{l}\text { Convection } \\
\text { electric field }\end{array}$ & $E$ & & $\bar{X}$ & Real time \\
\hline & $\begin{array}{c}\text { AFGL } \\
\text { precipitation } \\
\text { models }\end{array}$ & Satellite data & Geomagnetic indices & $\begin{array}{l}\text { Ion and electron } \\
\text { auroral precipitation } \\
\text { Conductivities }\end{array}$ & E & & & \\
\hline & IRI & $\begin{array}{c}\text { Ionosondes, } \\
\text { IS data } \\
\text { Topside sounders }\end{array}$ & $\begin{array}{c}\mathrm{F}_{10.7} \text { or } \\
\text { Sunspot number } \\
{[\mathrm{NmF} 2 \text { and } \mathrm{HmF} 2 \text {, }} \\
\text { or TEC }]\end{array}$ & $\begin{array}{c}\text { Electron and ion } \\
\text { densities and } \\
\text { temperatures }\end{array}$ & $E$ & $\mathrm{X}$ & $\begin{array}{c}\text { Mainly topside } \\
\text { densities }\end{array}$ & $\begin{array}{c}\text { Valid in } \\
\text { non auroral zone } \\
\text { and for quiet } \\
\text { conditions }\end{array}$ \\
\hline & $\begin{array}{l}\text { SLIM-FAIM } \\
\text { PIM }\end{array}$ & $\begin{array}{c}\text { outputs of } \\
\text { physical models }\end{array}$ & $\begin{array}{c}\mathrm{F}_{10.7} \\
\text { Geomagnetic indices }\end{array}$ & $\begin{array}{l}\text { Electron density } \\
\text { profiles }\end{array}$ & $E$ & $\mathrm{X}$ & & \\
\hline & $\begin{array}{c}\text { Profilers } \\
\text { (DGR derived) }\end{array}$ & $\begin{array}{l}\text { Data assimilation } \\
\text { (Ionosondes) }\end{array}$ & $\begin{array}{c}\mathrm{F}_{10.7} \text { or } \\
\text { Sunspot number } \\
\text { Ionosondes data }\end{array}$ & $\begin{array}{l}\text { Electron densities } \\
\text { profiles }\end{array}$ & $E$ & $X$ & $\begin{array}{c}\text { Mainly topside } \\
\text { density }\end{array}$ & $\begin{array}{c}\text { Development } \\
\text { co-ordination by } \\
\text { COST271 and ESA }\end{array}$ \\
\hline \multirow{2}{*}{$\begin{array}{l}\text { Thermo- } \\
\text { sphere }\end{array}$} & $\begin{array}{l}\text { MSIS } \\
\text { DTM }\end{array}$ & $\begin{array}{c}\text { Satellite data } \\
\text { from 1975-1983 } \\
+ \text { IS data for MSIS }\end{array}$ & $\begin{array}{c}\mathrm{F}_{10.7} \\
\text { Geomagnetic indices }\end{array}$ & $\begin{array}{l}\text { Neutral densities } \\
\text { and temperature }\end{array}$ & $E$ & & $\mathrm{X}$ & $\begin{array}{l}\text { Mostly valid at mid } \\
\text { and low latitudes }\end{array}$ \\
\hline & HWM & $\begin{array}{c}\text { Satellite data } \\
\text { from 1975-1983 } \\
\text { IS and inter- } \\
\text { ferometer data }\end{array}$ & $\begin{array}{l}\mathrm{F}_{10.7} \\
\text { Geomagnetic indices }\end{array}$ & Neutral wind & $E$ & & $\mathrm{X}$ & $\begin{array}{l}\text { Mostly valid at mid } \\
\text { and low latitudes }\end{array}$ \\
\hline
\end{tabular}

the reference flux chosen, and the interpolation formula. The coronal flux is also constrained to be at most $80 \%$ of the total.

Those models are very important for aeronomic computation. They allow one to develop fairly good physics. How- ever, they cannot take into account the variability at different wavelengths. Indeed, specific full measurements (for example, on board the space shuttle) clearly show that there is no linear variation with the decimetric index. On the contrary, some lines of the solar flux may increase with solar activity 
Table 3. Summary of non-operational physical model classes. The last column states their operational potentialities as foreseen today, if resources are available for operational development

\begin{tabular}{|c|c|c|c|c|c|}
\hline & Models & Method & Inputs & Outputs & $\begin{array}{l}\text { Operational } \\
\text { potentialities }\end{array}$ \\
\hline Sun & Solar atmosphere & MHD & Photospheric magnetic field & $\begin{array}{l}\text { Coronal magnetic field; } \\
\text { Eruptive phenomena }\end{array}$ & Long term \\
\hline \multirow{2}{*}{$\begin{array}{l}\text { Interplanetary } \\
\text { medium }\end{array}$} & $\begin{array}{c}\text { Solar Wind } \\
\text { Global Structure }\end{array}$ & MHD & $\begin{array}{c}\text { Plasma and magnetic field } \\
\text { at the Sun }\end{array}$ & $\begin{array}{c}\text { IMF, Plasma velocity, density } \\
\text { and temperature at } 1 \mathrm{AU}\end{array}$ & Long term \\
\hline & $\begin{array}{l}\text { propagation of } \\
\text { CMEs }\end{array}$ & MHD & $\begin{array}{c}\text { Plasma and magnetic field } \\
\text { at the Sun }\end{array}$ & $\begin{array}{l}\text { Properties of CMEs at } 1 \mathrm{AU} \\
\text { and beyond }\end{array}$ & Long term \\
\hline \multirow[b]{2}{*}{ Magnetosphere } & Global models & $\begin{array}{l}\text { MHD and/or } \\
\text { Kinetic }\end{array}$ & $\begin{array}{l}\text { IMF, solar wind velocity } \\
\text { and density at } 1 \mathrm{AU} \\
\text { Present status of the } \\
\text { magnetosphere }\end{array}$ & $\begin{array}{l}\text { Magnetic field and particle } \\
\text { distribution in the } \\
\text { magnetosphere }\end{array}$ & $\begin{array}{l}\text { Depend on } \\
\text { the model }\end{array}$ \\
\hline & Radiation belt & $\begin{array}{c}\text { Adiabatic } \\
\text { invariants } \\
\text { Fokker Planck } \\
\text { diffusion } \\
\text { equation }\end{array}$ & $\begin{array}{c}\text { Geomagnetic indices } \\
\text { Thermospheric } \\
\text { neutral densities } \\
\text { Cosmic neutron flux, Waves } \\
\text { Plasmaphere position }\end{array}$ & $\begin{array}{l}\text { Particle fluxes } \\
\text { Protons: } 0.1-300 \mathrm{MeV} \\
\text { Electrons: } 0.1-10 \mathrm{MeV}\end{array}$ & $\begin{array}{c}\text { Short term } \\
\text { for Salammbô }\end{array}$ \\
\hline \multirow[t]{2}{*}{$\begin{array}{l}\text { Ionosphere } \\
\text { Thermosphere }\end{array}$} & $\begin{array}{c}\text { Ionosphere } \\
\text { 1D and 3D models }\end{array}$ & $\begin{array}{c}\text { Fluid } \\
\text { description } \\
\text { (+Kinetic } \\
\text { Transport) }\end{array}$ & $\begin{array}{c}\mathrm{F}_{10.7} \\
\text { Thermospheric neutral } \\
\text { densities, temperature and winds } \\
\text { Geomagnetic indices } \\
\text { or Convection pattern } \\
\text { and Auroral Precipitation }\end{array}$ & $\begin{array}{l}\text { Electron and ion densities } \\
\text { and temperatures } \\
\text { Ion velocity }\end{array}$ & Short term \\
\hline & $\begin{array}{l}\text { 3D Coupled } \\
\text { Ionosphere } \\
\text { Thermosphere }\end{array}$ & $\begin{array}{c}\text { Fluid } \\
\text { description } \\
\text { Eulerian } \\
\text { approach }\end{array}$ & $\begin{array}{c}\mathrm{F}_{10.7} \\
\text { Geomagnetic indices } \\
\text { or Convection pattern } \\
\text { and Auroral Precipitation }\end{array}$ & $\begin{array}{l}\text { Neutral densities, } \\
\text { temperature and wind }\end{array}$ & Mid term \\
\hline
\end{tabular}

or decrease, sometimes drastically.

Finally, a radically different approach has been considered by Warren et al. (1996, 1998). They combined a spectral emission line database, solar emission distributions, and estimates from ground-based solar images of the fraction of the Sun covered by the various types of activity, to synthesise the irradiance. The aim was to provide a way to estimate the irradiance by means of the model, from the EUV line emission formed in the upper chromosphere, and in the lower transition region from the Ca II K-line. This approach made it possible for them to estimate the emission measure from a spectrum of a portion of the quiet solar disk measured with the Harvard instrument on Skylab, and compilations of atomic data (Warren et al., 1998). The irradiance spectrum from 50-1200 $\AA$ was then computed for the quiet Sun, with the contributions of optically thick emission lines and continua included empirically. A comparison with the empirical models described above indicates relatively good agreement among fluxes of emission lines formed in the solar chromosphere and transition region. A factor of typically 2 is found with the fluxes for coronal emission lines.

\section{Model synthesis}

Tables 2 and 3 summarise the main models described in Sect. 1, their inputs and their outputs. Table 2 presents the pre-operational and operational models. It is not restricted to the models that are effectively used in operational centres, but includes those that could be used operationally today, as are, for example, most of the empirical models. This table does not, however, include all the models described in the previous sections, but is limited to either recent models or the ones most often used for the same outputs. A letter indicates if the model is a physical one $(P)$ or a semi-empirical or empirical one $(E)$. We have also indicated whether development of the model itself or availability of new observations is the most crucial for its improvement. The type of data for which the model is based upon is also indicated (column 3 ), and finally, some remarks are added (column 4). Most of these models use the geomagnetic indices as inputs. The SuperDARN convection model and the ionospheric profilers are based on data assimilation techniques, in order to provide a 3-D description of a given parameter using localised observations as inputs. It should be noted here that new methods are now developed for extracting thermospheric parameters (neutral composition, temperature, total density, winds) from routine ionospheric observations (ground-based vertical sounding, TEC data).

Table 3 presents a summary of non-operational physical models. Contrarily to Table 2, this table deals with classes of models and not with specific models. All models require either improvements or new observations - including for val- 
Table A1: Members of the consortium lead by ALCATEL Space and LPCE

\begin{tabular}{|c|c|}
\hline Companies & Key personnel \\
\hline ALCATEL Space Industries, Cannes, France & B. HUET ${ }^{1}$; O. PANSART; P. KAMOUN \\
\hline $\begin{array}{l}\text { Laboratoire de Physique \& Chimie de } \\
\text { l'environnement, Orléans, France }\end{array}$ & F. LEFEUVRE ${ }^{1}$; P. GILLES; T. DUDOK DE WIT \\
\hline British Antartic Survey, Cambridge, U.K. & R. HORNE ${ }^{1}$ \\
\hline $\begin{array}{l}\text { Swedish Institute of Space Physics - } \\
\text { IRF, Lund, Sweden }\end{array}$ & H. LUNDSTEDT ${ }^{1}$ \\
\hline $\begin{array}{l}\text { Mullard Space Science Laboratory - } \\
\text { UCL, London, U.K. }\end{array}$ & A. COATES ${ }^{1}$; R. BENTLEY; N. CROSBY \\
\hline ESYS, Surrey, U.K. & A. SHAW $^{1}$ \\
\hline $\begin{array}{l}\text { Observatoire de Paris - } \\
\text { LPSH, Meudon, France }\end{array}$ & M. PICK $^{1}$ \\
\hline $\begin{array}{l}\text { Laboratoire de Planétologie de Grenoble, } \\
\text { Grenoble, France }\end{array}$ & J. LILENSTEN ${ }^{1}$; C. LATHUILLERE \\
\hline Imperial College, London, U.K. & P. CARGILL ${ }^{1}$ \\
\hline $\begin{array}{l}\text { University of Greifswald - EMAU, } \\
\text { Greifswald, Germany }\end{array}$ & F. JANSEN ${ }^{1}$ \\
\hline
\end{tabular}

(1): contact persons

idation purposes - or both. Most of them are today scientific codes developed for research purposes. The last column states their operational potentialities as foreseen today, if resources are available for operational development. Ring current models, as defined in Sect. 1, are not included in this table, because the data needed at the boundary make it almost impossible to use for operational space weather applications.

\section{Conclusion}

The large variability of the solar terrestrial system limits the efficiency of empirical models, while progress in space weather requires the development of models that rely on basic physical principles controlling the behaviour of the SunEarth interaction. Achieving the development of such quantitative physical models is one of the main challenges for space weather issues, and more generally, for solar terrestrial physics. However, one can foresee a long time before this is achieved. The short overview of the state of the art presented in the previous sections shows that this delay is highly dependant on the considered sub-system.

Space weather aims at routinely producing forecasts of relevant parameters. Before the development of operational versions of physical models, this will be achieved by means of hybrid models involving simultaneously physical codes, artificial intelligence-based codes, and empirical models. Such a hybrid approach is presently, and likely to remain for a long time the most promising way of development of operational models. More developments and improvements of empirical models remain, therefore, mandatory.

These developments imply routine availability of relevant direct measurements or scientifically agreed proxies. In many cases, homogeneous and long enough data series are necessary to assess the models in the various situations that can be encountered in solar terrestrial physics. This is already the case for some ground-based measurements, for example, ionosonde measurements and in space for the GPS satellite data over the last few years. However, it is not yet the case for most in situ measurements on board satellites, inside or outside the magnetosphere. In addition, the indices monitoring solar and geomagnetic activity have not, at present, the required characteristics to comply with the requirements of space weather: for example, time and/or space resolution are not good enough (magnetic indices), measured quantity is not well suited (solar decimetric index). The development of new indices with a better time and/or space resolution, or based on more relevant quantities has already been initiated in the scientific community.

Acknowledgements. We thank the Consortium team for fruitful scientific discussions. We also thank P. Cargill for specific input. This work has been initiated in the frame of the preparation of a workshop of the French "Programme National Soleil-Terre".

The Editor in Chief thanks R. Schwenn and another referee for their help in evaluating this paper. 


\section{Annex 1:}

ESA study for a space weather program - ALCATEL driven consortium

Areas addressed within this ESA study include:

- the user's requirements assessment and market analysis; the parameters needed for space weather and their associated measurement requirements;

- the combined space segment/ground segment scenarios and hardware assessment for meeting the specific needs of an operational space weather system;

- the prediction service definition and its prototyping, including models evaluation;

- the programme development assessment with its European organisation.

The main outcomes expected are comprehensive answers to the following fundamental questions:

- For which user shall a space weather service be developed and in which time frame?

- Which components shall be deployed and with which complexity?

- When shall/can a space weather service be operational?

- How shall a space weather service be implemented, i.e. with which organisation and coordination within Europe and which level of autonomy?

For any further information concerning the tasks performed by the consortium, the reader may refer to the following web site: http://www.european-space-weather-at.com.

\section{References}

Abel B. and Thorne, R. M.: Electron scattering loss in Earth's inner magnetosphere. 1. Dominant physical processes, J. Geophys. Res., 103, 2385-2396, 1998a.

Abel B. and Thorne, R. M.: Electron scattering loss in Earth's inner magnetosphere. 2. Sentivity to model parameters, J. Geophys. Res., 103, 2397-2407, 1998b.

Alissandrakis, C. E.: On the computation of constant alpha forcefree magnetic field, Astron. Astrophys., 100, 197-200, 1981.

Amari, T. and Démoulin, P.: in: Proceedings of the Workshop "Méthodes de détermination des champs magnétiques solaires et stellaires", Observatoire de Paris, 187-209, 1992.

Amari, T., Aly, J.-J., Luciani, J.-F., Boulmezaoud, T. Z., and Mikic, Z.: Reconstructing the solar coronal magnetic field as a forcefree magnetic field, Solar Physics, 174, 129-149, 1997.

Amari, T., Boulmezaoud, T. Z., and Maday, Y.: A regularization method for the extrapolation break of the photospheric solar magnetic field. I. Linear force-free field, Astron. Astrophysis., 339, 252-260, 1998.
Amari, T., Luciani, J. F., Mikic, Z., and Linker, J.: A Twisted Flux Rope Model for Coronal Mass Ejections and Two-Ribbon Flares, Astrophysical Journal, 529, L49-L52, 2000.

Anderson, D. N., Mendillo, M., and Herniter, B.: A Semi-Empirical Low-Latitude Ionospheric Model, Radio Sci. 22, 292-306, 1987.

Anderson, D. N., Forbes, J. M., and Codrescu, M.: A Fully Analytical, Low- and Middle-Latitude Ionospheric Model, J. Geophys. Res., 94, 1520-1524, 1989.

Anderson, D. N., Decker, D. T., and Valladares, C. E.: Global Theoritical Ionospheric Model (GTIM), STEP Handbook of ionospheric models, (Ed.) Schunk, R. W., 133-152, 1996.

Aulanier, G., Démoulin, P., Schmieder, B., Fang, C., and Tang, Y. H.: Magnetohydrostatic Model of a Bald-Patch Flare, Solar Physics, 183, 369-388, 1998.

Barlier, F., Berger, C., Falin, J.-L., Kockarts, G., and Thuillier, G.: A thermospheric model based on satellite drag data, Ann. Geophysicae, 34, 9-24, 1978.

Baty, H. and Heyvaerts, J.: Electric current concentration and kink instability in line-tied coronal loops, Astronomy and Astrophysics, 308, 935-950, 1996.

Baussart N., Simonet, F., Réveillé, T., Bertrand, P., Gjizzo, A., André, R., and Lefeuvre, F.: Investigation of the dynamics of enhanced natural and artificial electron fluxes in the radiation belts: influence of the whistler mode wave model, Fifth European Conference on Radiation and its Effects on Components and Systems (RADECS 99), pp 1-5, IEEE, Piscataway, NJ, USA, 2000.

Berger, C., Biancale, R., III, M., and Barlier, F.: Improvement of the empirical thermospheric model DTM: DTM94 - a comparative review of various temporal variations and prospects in space geodesy applications, J. of Geodesy, 72, 161-178, 1998.

Beutier T., Boscher, D., and France, M.: Salammbô: A threedimensional simulation of the proton radiation belt, J. Geophys. Res., 100, 17 181-17 188, 1995.

Beutier T. and Boscher, D.: "A three-dimensional analysis of the electron radiation belt by the Salammbô code", J. Geophys. Res., 100, 14 853-14 861, 1995.

Bilitza, D.: (Ed.) International Reference Ionosphere 1990, NSSDC 90-22, Greenbelt, Maryland, 1990.

Bourdarie S., Boscher, D., Beutier, T., Sauvaud, J.-A., and Blanc, M.: "Electron and proton radiation belt dynamic simulations during storm periods: a new asymmetric convection-diffusion model”, J. Geophys. Res., 102, 17 541-17 552, 1997.

Bradley, P. A. and Dudeney, J. R.: A simple model of the vertical distribution of electron concentration in the ionosphere", J. Atmos. Terr. Phys., 35, 2131-2146, 1973.

Brautigam D. H., Gussenhoven, M. S., and Mullen, E. G.: Quasistatic model of outer zone electrons, IEEE Trans. Nucl. Sci., 39, 1797-1803, 1992.

Cargill P. J., Schmidt, J., Spicer, D. S., and Zalesak, S. T.: Magnetic structure of overexpanding coronal mass ejections: Numerical models, J. Geophys. Res., 105, 7509-7519, 2000.

Chen, M. W., Lyons, L., and Schultz, M.: Simulation of phase and space distributions of storm time proton ring current, J. Geophys. Res., 99, 5745-5759, 1994.

Chiu, Y. T.: An Improved Phenomenological Model of Ionospheric Concentration, J. Atmos. Terr. Phys., 37, 1563-1570, 1975.

Chiu, Y. T. and Hilton, H. H.: Exact Green's function method of solar force-free magnetic-field computations with constant alpha. ITheory and basic test cases, Astrophysis. J., 212, 873-885, 1977.

Codrescu, M. V., Fuller-Rowell, T. J., and Kutiev, I. S.: Modelling the F-layer during specific geomagnetic storms, J. Geophys. Res., 102, 14 315-14330, 1997. 
Cuperman, S., Ofman, L., and Semel, M.: The absolute value and sign of the function alpha $(r)$ in the force-free magnetic field modelling of photospheric observations, Astron. Astrophysis., 227, 227-234, 1990.

Daglis, I. O., Thorne, R. M., Baumjohann, W., and Orsini, S.: The terrestrial ring current: origin, formation, and Decay, Rev. Geophys., 37, 407-438, 1999.

Daniell, R. E., Jr., Brown, L. D., Anderson, D. N., Fox, M. W., Doherty, P. H., Decker, D. T., Sojka, J. J., and Schunk, R. W.: Parameterized ionospheric model: A global ionospheric parameterization based on first principles models, Radio Science, 30, 1499-1510, 1995.

Delcourt, D. C., Sauvaud, J.-A., and Moore, T. E.: Cleft contribution to ring current formation, J. Geophys. Res., 95, $20937-$ 20 943, 1990a.

Delcourt, D. C., Sauvaud, J.-A., and Pedersen, A.: Dynamics of single-particle orbits during substorm expansion phase, J. Geophys. Res., 95, 20 853-20 865, 1990b.

Demoulin, P., Cuperman, S., and Semel, M.: Determination of force-free magnetic fields above the photosphere using threecomponent boundary conditions. II - Analysis and minimization of scale-related growing modes and of computational induced singularities, Astron. Astrophysis., 263, 351-360, 1992.

Demoulin P., Bagala, L. G., Mandrini, C. H., Henoux, J. C., and Rovira, M. G.: Quasi-separatrix layers in solar flares. II. Observed magnetic configurations, Astron. Astrophysis., 325, 305317, 1997.

DeVore, C. R. and Antiochos, S. K.: Dynamical Formation and Stability of Helical Prominence Magnetic Fields, Astrophysical Journal, 539, 954-963, 2000.

Di Giovanni, G. and Radicella, S. R.: An analytical model of the electron concentration profile in the ionosphere, Adv. Space Res., 10, 11, 27-30, 1990.

Dmitruk, P., Gómez, D. O., and Deluca, E. E.: Magnetohydrodynamic Turbulence of Coronal Active Regions and the Distribution of Nanoflares, Astrophysical Journal, 505, 974-983, 1998.

Dudeney, J. R.: An improved model of the variation of electron concentration with height in the ionosphere, J. Atmos. Terr. Phys., 40, 195-203, 1978.

Feldstein, Ya. I., Levitin, A. E., Faermark, D. S., Afonina, R. G., Belov, B. A., and Gaidukov, V. Y.: Electric fields and potential patterns in the high-latitude ionosphere for different situations in interplanetary space, Planet. Space Sci., 32, 907-923, 1984.

Fisk, L. A., Wenzel, K.-P., Balogh, A., Burger, R. A., Cummings, A. C., Evenson, P., Heber, B., Jokipii, J. R., Krainev, M. B., Kóta, J., Kunow, H., Le Roux, J. A., McDonald, F. B., McKibben, R. B., Potgieter, M. S., Simpson, J. A., Steenberg, C. D., Suess, S., Webber, W. R., Wibberenz, G., Zhang, M., Ferrando, P., Fujii, Z., Lockwood, J. A., Moraal, H., and Stone, E. C.: Global Processes that Determine Cosmic Ray Modulation, Space Science Reviews, 83, 179-214, 1998.

Fok, M.-C., Kozyra, J. U., Nagy, A. F., Rasmussen, C. E., and Khazanov, G. V.: Decay of equatorial ring current ions and associated aeronomical consequences, J. Geophys. Res., 98, 19381-19393, 1993.

Fok, M.-C., Moore, T. E., and Delcourt, D. C.: Modeling of inner plasma sheet and ring current during substorms, J. Geophys. Res., 104, 14 557-14 569, 1999a.

Fok, M.-C., Moore, T. E., Slinker, S., Fedder, J. A., and Delcourt, D. C.: Nonadiabatic behaviour of heavy ions in the magnetotail during IMF southward turning, AGU Fall Meeting, San Francisco, EOS Trans. AGU (abstract), 1999 b.
Förster, M., Namgaladze, A. A., and Yurik, R. Y.: Thermospheric composition changes deduced from geomagnetic storm modeling, Geoph. Res. Lett., 26, 2625-2628, 1999.

Freeman, J. W., Wolf, R. A., Spiro, R. W., Hausman, B. A., Bales, B., and Lambour, R.: A real time magnetospheric specification model: Magnetospheric Specification and Forecast Model (MSFM) final report, USAF contract F19628-90-K-0012, Rice Univ., Houston, Texas, 1994.

Fryxell, B., Olson, K., Ricker, P., Timmes, F. X., Zingale, M., Lamb, D. Q., MacNeice, P., Rosner, R., Truran, J. W., and Tufo, H.: FLASH: An Adaptive Mesh Hydrodynamics Code for Modeling Astrophysical Thermonuclear Flashes, The Astrophysical Journal Supplement Series, 131, 273-334, 2000.

Fuller-Rowell, T. J., Rees, D., Quegan, S., Moffett, R. J., Codrescu, M. V., and Millward, G. H.: "A Coupled ThermosphereIonosphere Model (CTIM)", STEP Handbook of ionospheric models, (Ed.) Schunk, R., 217-238, 1996.

Fuller-Rowell T. J., Matsuo, T., Codrescu, M. V., and Marcos, F. A.: Modeling Thermospheric Neutral Density Waves and Holes in Response to High Latitude Forcing, Adv. Sp. Res., 24, 14471458, 1999.

Fuller-Rowell T. J., Codrescu, M. V., and Wilkinson, P.: Quantitative modeling of the ionospheric response to geomagnetic activity, Ann. Geophysicae, 18, 766-781, 2000.

Galand M., Fuller-Rowell, T. J., and Codrescu, M. V.: Response of the upper atmosphere to auroral protons, J. Geophys. Res., 106, 127-140, 2001.

Galtier, S., Politano, H., and Pouquet, A.: Self-Similar Energy Decay in Magnetohydrodynamic Turbulence, Physical Review Letters, 79, 2807-2810, 1997.

Grad, H. and Rubin, H.: Proc. 2nd Intern. Conf on Peaceful Uses of Atomic Energy, 31, 190, Geneva, United Nations, 1958.

Grappin, R., Léorat, J., and Buttighoffer, A.: Alfvén wave propagation in the high solar corona, Astronomy and Astrophysics, 362, 342-358, 2000.

Gussenhoven M. S., Mullen, E. G., Violet, M. D., Hein, C., Bass, J., and Madden, D.: CRRES high energy proton flux maps, IEEE transactions on Nuclear Science, 40, 1450-1457, 1993.

Hagan, M. E. and Roble, R. G.: Modeling diurnal tidal variability with the NCAR TIME-GCM, J. Geophys. Res., in press, 2002.

Hardy D. A., Gussenhoven, M. S., and Raistrick, R.: Statistical and Functional Representations of the Pattern of Auroral Energy Flux, Number Flux, and Conductivity, J. Geophys. Res., 92, 12 275-12 294, 1987.

Hardy D. A., Gussenhoven, M. S., and Brautigam, D.: A Statistical Model of Auroral Ion Precipitation, J. Geophys. Res. 94, 370392, 1989.

Hedin A. E.: MSIS-86 Thermospheric Model, J. Geophys. Res. 92, 4649-4667, 1987.

Hedin A. E.: Extension of the MSIS Thermospheric Model into the Middle and Lower Atmosphere, J. Geophys. Res. 96, 1159$1172,1991$.

Hedin A. E., Spencer, N. W., Biondi, M. A., Burnside, R. G., Hernandez, G., and Johnson R. M.: Revised Global Model of Thermosphere Winds Using Satellite and Ground-Based Observations, J. Geophys. Res. 96, 7657-7688, 1991.

Hedin A. E., Fleming, E. L., Manson, A. H., Schmidlin, F. J., Avery, S. K., Clark, R. R., Franke, S. J., Fraser, G. J., Tsuda, T., Vial, F., and Vincent, R. A.: Empirical wind model for the upper, middle and lower atmosphere, J. Atmos. Terr. Phys., 58, 1421-1447, 1996.

Heelis R. A., Lowell, J. K., and Spiro, R. W.: A Model of the High- 
Latitude Ionospheric Convection Pattern, J. Geophys. Res. 87, 6339-6345, 1982.

Heppner, J. P. and Maynard, N. C.: Empirical High-Latitude Electric Field Models, J. Geophys. Res. 92, 4467-4489, 1987.

Hilmer, R. V. and Voigt, G.-H.: A magnetospheric magnetic field model with flexible internal current systems driven by independent physical parameters, J. Geophys. Res., 100, 5613-5626, 1995.

Hinteregger, H. E., Bedo, D. E., and Manson, J. E.: The EUV spectrophotometer on Atmosphere Explorer, Radio Sci., 8, 349-354, 1973.

Hinteregger, H. E.: Representation of solar EUV fluxes for aeronomical applications, Adv. Space Res, 1, 39-52, 1981.

Hinteregger, H. E. and Katsura, F.: Observationnal, reference and model data on solar EUV, from measurements on AE-E, Geophys. Res. Lett., 8, 1147-1150, 1981.

Hochegger G., Nava, B., Radicella, S. M., and Leitinger, R.: A family of ionospheric models for different users, Phys. Chem. Earth, 25, 307-310, 2000.

Holt J. M., Wand, R. H., Evans, J. V., and Oliver, W. L.: Empirical Models for the Plasma Convection at High Latitudes from Millstone Hill Observations, J. Geophys. Res. 92, 203-212, 1987.

Hultqvist, B., Øieroset, M., Pashmann, G., and Treumann, R. (Eds.): Magnatospheric plasma sources and losses, Space Science Series of ISSI, vol. 6, 482 pp., Kluwer Academic Publishers, 1999 (published also in Space Sci. Rev., 88, 355-392, 1999).

Hurricane, O. A., Pellat, R., and Coroniti, F. V.: A new approach to low-frequency "MHD-like" waves in magnetospheric plasmas, J. Geophys. Res., 100, 19421-19428, 1995.

Huston, S. L., Kuck, G. A., and Pfitzer, K. A.: Solar cycle variations of the low altitude trapped proton fluxes, Adv. Space Res., 21, 1625-1634, 1998.

Israelevich, P. L., Gombosi, T. I., Ershkovich, A. I., Hansen, K. C., Groth, C. P. T., DeZeeuw, D. L., and Powell, K. G.: MHD simulation of the three-dimensional structure of the heliospheric current sheet, Astronomy and Astrophysics, 376, 288-291, 2001.

Janhunen, P.: GUMICS-3 - A global ionosphere-magnetosphere coupling simulation with high ionospheric resolution, in Environmental modelling for Space-based applications, ESA SP-392, 233-239, 1996.

Lambour, R. L., Weiss, L. A., Elphic, R. C., and Thomsen, M. F.: Global modelling of the plasmasphere following storm sudden commencements, J. Geophys. Res., 102, 24 351-24 368, 1997.

Le Contel O., Pellat, R., and Roux, A.: Self-consistent quasi-static radial transport during the substorm growth phase, J. Geophys. Res., 105, 12 929-12 944, 1999a.

Le Contel O., Pellat, R., and Roux, A.: Self-consistent quasi-static parallel electric field associated with substorm growth phase, J. Geophys. Res., 105, 12 945-12 955, 1999b.

Lefeuvre, F., André, R., Simonet, F., and Baussart, N.: On the modelling of low frequency waves in the equatorial regions of the plasmasphere, Fall meeting of AGU, SM52A-31, 2000.

Lilensten J. and Blelly, P. L.: The TEC and F2 parameters as tracers of the ionosphere and thermosphere, JASTP, in press, 2002.

Lionello, R., Velli, M., Einaudi, G., and Mikic, Z.: Nonlinear Magnetohydrodynamic Evolution of Line-tied Coronal Loops, Astrophysical Journal, 494, 840-850, 1998.

Low B. C.: Three-dimensional structures of magnetostatic atmospheres. IV - Magnetic structures over a solar active region, Astrophys. J., 399, 1, 300-312, 1992.

Matsumoto, R., Tajima, T., Shibata, K., and Kaisig, M.: Threedimensional magnetohydrodynamics of the emerging magnetic flux in the solar atmosphere Astrophysical Journal, 414, 357371, 1993.

Mikic Z. and Linker, J. A.: Disruption of coronal magnetic field arcades, Astrophys. J., 430, 898-912, 1994.

Millward G. H., Moffett R. J, Quegan, S. and Fuller-Rowell, T. J.: "A Coupled Thermosphere-Ionosphere-Plasmasphere Model (CTIP)", STEP Handbook of Ionospheric Models, (Ed) Schunk, R. W., 239-279, 1996.

Millward, G. H., Muller-Wodarg, I. C. F., and Aylward, A. D.: "The influence of thermospheric tides on equatorial dynamics: CTIP model results", J. Geophys. Res., (in press), 2000.

Muller-Wodarg I. C. F., Aylward, A. D., and Fuller-Rowell, T. J.: "Tidal oscillations in the thermosphere: a theoretical investigation of their sources", J. Atmos. Terr. Phys., (in press), 2000.

Mobarry, C. M., Fedder, J. A., and Lyon, J. G.: Equatorial plasma convection from global simulations of the Earth's magnetosphere, J. Geophys. Res., 101, 7859-7874, 1996.

Namgaladze, A. A., Korenkov, Yu. N., Klimenko, V. V., Karpov, I. V., Surotkin, V. A., and Naumova, N. M.: Numerical modelling of the thermosphere-ionosphere-protonosphere system, J. Atmos. Terr. Phys., 53, 1113-1124, 1991.

Namgaladze, A. A., Förster, M., and Yurik, R. Y.: Analysis of the positive ionospheric response to a moderate geomagnetic storm using a global numerical model, Ann. Geophysicae, 18, 461477, 2000.

Odstrcil, D. and Pizzo, V.: Distortion of the interplanetary magnetic field by three-dimensional propagation of coronal mass ejections in a structured solar wind, J. Geophys. Res., 104, 28 225-28 239, 1999.

Papitashvili, V. O. and Rich, F. J.: High-latitude ionospheric convection models derived from DMSP ion drift observations and parameterised by the IMF strength and direction, J. Geophys Res., 107, in press, 2002.

Parker E. N.: Interplanetary Dynamical Processes, New York, Interscience Publishers, 1963.

Pellat R., Hurricane, O. A., and Coroniti, F. V.: Multipole stability revisited, Phys. Plasmas, 1, 3502-3504, 1994.

Peymirat C. and Fontaine, D.: Numerical simulation of magnetopseric convection including the effect of field aligned currents and electron precipitation, J. Geophys. Res., 99, 11 155-11 176, 1994.

Peymirat C., Richmond, A. D., Emery, B. A., and Roble, R. G.: A magnetopshere-thermopshere-ionosphere electrodynamics general circulation model, J. Geophys. Res, 103, 17567-17477, 1998.

Picone, J. M., Hedin, A. E., Drob, D. P., Meyer, R. R., Lean, J., Nicholas, A. C., and Thonnard, S. E.: Enhanced empirical models of the thermosphere, Phys. Chem. Earth, 25, 5/6, 537-542, 2000.

Pizzo V. J.: A three-dimensional model of corotating streams in the solar wind. III - Magnetohydrodynamic streams, J. Geophys Res., 87, 4374-4394, 1982.

Pizzo, V. J.: The evolution of corotating stream fronts near the ecliptic plane in the inner solar system. II - Three-dimensional tilteddipole fronts, J. Geophys. Res., 96, 5405-5420, 1991.

Pridmore-Brown, D.: Aerospace report no ATR-81(7813)-1, The Aerospace Corporation, El Sequndo, California, USA, 1981.

Priest, E. R.: Solar magneto-hydrodynamics, D. Reidel Publishing Compagny, Dordrecht, Holland, 1982.

Radicella, S. M. and Zhang, M. L.: The improved DGR analytical model of electron concentration height profile and total electron content in the ionosphere, Annali di Geofisica, 38, 1, 35-41, 
1995.

Raeder, J., Berchem, J., Ashour-Abdalla, M., Franck, L. A., Paterson, W. R., Ackerson, K. L., Kokubun, S., Yamamoto, T., and Slavin, J. A.: Boundary layer formation in the magnetotail: geotail observations and comparisons with a global MHD simulation, Geophys. Res. Lett., 24, 951-954, 1997.

Rawer, K.: Replacement of the present sub-peak plasma concentration profile by a unique expression, Adv. Space Res., 2, 183-192, 1982.

Rich F. J. and Maynard, N. C.: Consequences of Using Simple Analytical Functions for the High-Latitude Convection Electric Field, J. Geophys. Res., 94, 3687-3701, 1989.

Richard P. G. and Torr, D. J.: The Field Line Interhemispheric Plasma Model, STEP Handbook of ionospheric models, (Ed) Schunk, R. W., 207-216, 1996.

Richard P., Fennelly, G., and Torr, D. J.: EUVAC: a solar EUV flux model for aeronomic calculation, J. Geophys. Res., 99, 89818992, 1994.

Richmond, A. D., Ridley, E. C., and Roble, R. G.: A thermosphere/ionosphere general circulation model with coupled electrodynamics, Geophys. Res. Lett., 19, 601-604, 1992.

Richmond, A. D.: Assimilative mapping of ionospheric electrodynamics, Adv. Space Res., 12, 669-668, 1992.

Riley P., Gosling, J. T., Weiss, L. A., and Pizzo, V. J.: The tilts of corotating interaction regions at midheliographic latitudes, J. Geophys. Res., 101, 24 349-24 357, 1996.

Riley P., Gosling, J. T., and Pizzo, V. J.: A two-dimensional simulation of the radial and latitudinal evolution of a solar wind disturbance driven by a fast, high-pressure coronal mass., J. Geophys. Res., 102, 14 677-14 685, 1997.

Roble R. G and Ridley, E. C.: A thermosphere-ionospheremesosphere-electrodynamics general circulation model (timeGCM): Equinox solar cycle minimum simulations (30-500 km), Geoph. Res. Lett., 21, 417-420, 1994.

Roumeliotis, G.: The "Stress-and-Relax" method for reconstructing the coronal magnetic field from vector magnetograph data, Astrophys. J., 473, 1095-1103, 1996.

Sakurai, T.: Computational modeling of magnetic fields in solar active regions, Space Sci. Rev. 51, 11-48, 1989.

Sakurai, T.: Calculation of force-free magnetic field with non constant alpha, Solar Phys., 69, 343-359, 1981.

Sawyer, D. M. and Vette, J. I.: AP-8 Trapped Proton Environment for Solar Maximum and Solar Minimum, NSSDC/WDC-A-R \& S, 76-06, 1976.

Schoendorf J., Aylward, A. D., and Moffett, R. J.: "Modelling high-latitude electron densities with a coupled thermosphereionosphere model", Ann. Geophysicae, 14, 1391-1402, 1996.

Schunk, R. W.: Mathematical structure of transport equations for multispecies flows, Rev. Geophys. and Space Phys., 15, 429445, 1977.

Schunk, R. W.: STEP Handbook of ionospheric models, (Ed.) Schunk, R. W., 1996.

Schunk, R. W. and Sojka, J. J.: USU model of the global ionosphere, STEP Handbook of ionospheric models, (Ed.) Schunk, R. W., 153-172, 1996.

Schmidt, H. U.: in Physics of Solar Flares, NASA SP 50, 107, 1964.

Shepherd S. G. and Rhuohoniemi, J. M.: Electrostatic potential patterns in the high latitude ionosphere constrained by SuperDARN measurements, J. Geophys. Res., 23 005-23 014, 2000.

Shue, J.-H., Chao, J. K., Fu, H. C., Russel, C. T., Song, P., Khurana, K. K., and Singer, H. J.: A new functional form to study the solar wind control of the magnetopause size and shape, J. Geophys.
Res., 102, 9497-9511, 1997.

Slavin, J. A. and Holzer, R. E.: Solar wind flow about terrestrial planets -1 . Modelling bow shock position and shape, J. Geophys. Res., 86, 11401-11418, 1981.

Smets, R.: Dynamique des electrons dans les regions de transitions de la magnetosphere terrestre, Thèse de l'Université Paris Sud XI, 1998.

Stone, J. M. and Norman, M. L.: ZEUS-2D: A radiation magnetohydrodynamics code for astrophysical flows in two space dimensions. I - The hydrodynamic algorithms and tests, Astrophys. J. Supplement Series, 80, 753-790, 1992.

Szuszczewicz E. P., Blanchard, P., Wilkinson, P., Crowley, G., Fuller-Rowell, T. J., Richards, P., Abdu, M., Bullett, T., Hanbaba, R., Lebreton, J. P., Lester, M., Lockwood, M., Millward, G., Wild, M., Pulinets, S., Reddy, B. M., Stanislawska, I., Vannaroni, G., and Zolesi, B.: The first real-time worldwide ionospheric predictions network: an advance in support of spaceborne experimentation, on-line model validation, and space weather, Geoph. Res. Lett., 25, 449-452, 1998.

Tobiska, W. K.: Revised solar extreme ultraviolet flux model, J. Atmos. Terr. Phys., 53, 1005-1018, 1991.

Tobiska, J. R. and Eparvier, F.: EUV 97: improvements to EUV irradiance modeling in the soft X-ray and FUV, Sol. Phys., 177, 147-159, 1998.

Tobiska, W. K., Woods, T., Eparvier, F., Viereck, R., Floyd, L., Bouwer, D., Rottman, G., and White, O. R.: "The SOLAR2000 empirical solar irradiance model and forecast tool," J. Atm. Solar Terr. Phys., 62, 1233-1250, 2000.

Torr, M. R. and Torr, D. J.: Ionization frequencies for major thermospheric constituents as a function of solar cycle 21, Geoph. Res. Lett., 6, 771-774, 1979.

Torr, M. R. and Torr, D. J.: Ionization frequencies for solar cycle 21: Revised, J. Geophys. Res. 90, 6675-6678, 1985.

Tsyganenko, N. A.: Quantitative models of the magnetospheric magnetic field: methods and results, Space Sci. Rev., 54, 75186, 1990.

Tsyganenko, N. A.: Modelling of Earth's magnetospheric field confined with a realistic magnetopause, J. Geophys. Res., 100, 5599-5612, 1995.

Vandas M., Fischer, S., Dryer, M., Smith, Z., AND Detman, T. J.: Simulation of magnetic cloud propagation in the inner heliosphere in two dimensions 2. A loop parallel to the ecliptic plane and the role of helicity, J. Geophys. Res., 101, 2505-2510, 1996.

Vette, J. I.: The AE-8 Trapped Electron Model Environment, NSSDC/WDC-A-R\&S, 91-24, 1991.

Walker, R. J., Ogino, T., Raeder, J., and Ashour-Abdalla, M.: A global magnetohydrodynamic simulation of the magnetosphere when the interplanetary magnetic field is southward: the onset of magnetotail reconnection, J. Geophys. Res., 98, 17 235-17 249, 1993.

Wang, Y.-M., and Sheeley, Jr., N. R.: On potential field models of the solar corona, Astrophys. J., 392, 310-319, 1992.

Warren, H. P., Mariska, J. T., Lean, J., Marquette W. and Johannesson, A.: Modeling solar extreme ultraviolet irradiance variability using emission measure distribution, Geoph. Res. Lett., 23, 2207-2210, 1996.

Warren, H. P., Mariska, J. T., and Lean, J.: A new reference spectrum for the EUV irradiance of the quiet sun. 1. Emission measure formulation, J. Geophys. Res., 103, 12 077-12 089, 1998.

Weimer, D. R.: A flexible, IMF dependent model of high-latitude electric potentials having "space weather" applications, Geophys. Res. Lett., 23, 2549-2552, 1996. 
Witasse, O., Lilensten, J., Lathuillere, C., and Blelly, P. L.: Modeling the OI 630.0 and $557.7 \mathrm{~nm}$ thermospheric dayglow during EISCAT-WINDII coordinated measurements, J. Geophys. Res., 104, 24 639-24 655, 1999.

Wu, S. T., Sun, M. T., Chang, H. M., Hagyard, M. J., and Gary, G. A.: On the numerical computation of nonlinear force-free magnetic fields, Astrophys. J, 362, 698-708, 1990.
Zhang S. R., Huang, X., Su, Y., and Radicella, S. M.: A physical model for one-dimension and time-dependent ionosphere. Part I. Description of the model, Annali di Geofisica, 36, 5/6, 105-110, 1993.

Zhang S. R. and Radicella, S. M.: A physical model for onedimension and time-dependent ionosphere. Part II. Results and discussion, Annali di Geofisica, 36, 5/6, 111-117, 1993. 